\title{
Remote Substituent Effects on the Stereoselectivity and Organocatalytic Activity of Densely Substituted Unnatural Proline Esters in Aldol Reactions
}

\author{
María de Gracia Retamosa, ${ }^{[a]}$ Abel de Cózar, ${ }^{[a, b]}$ Mirian Sánchez, ${ }^{[a]}$ José I. Miranda, ${ }^{[c]}$ \\ José M. Sansano, ${ }^{[d]}$ Luis M. Castelló, ${ }^{\text {dd] }}$ Carmen Nájera, ${ }^{[\mathrm{dl}}$ Ana I. Jiménez, ${ }^{\text {le] }}$ \\ Francisco J. Sayago, ${ }^{[\mathrm{el}}$ Carlos Cativiela, ${ }^{\text {[e] }}$ and Fernando P. Cossío*[a]
}

Keywords: Organocatalysis / Aldol reactions / Kinetics / Reaction mechanisms / Transition states

The organocatalytic activities of highly substituted proline esters obtained through asymmetric [3+2] cycloadditions of azomethine ylides derived from glycine iminoesters have been analyzed by ${ }^{19} \mathrm{~F}$ NMR and through kinetic isotope effects. Kinetic rate constants have been determined for unnatural proline esters incorporating different substituents. It has been found that exo-L and endo-L unnatural proline methyl esters yield opposite enantiomers in aldol reactions between cyclic ketones and aromatic aldehydes. The combined results reported in this study show subtle and remote effects that determine the organocatalytic behavior of these synthetic but readily available amino acid derivatives. These data can be used as design criteria for the development of new pyrrolidine-based organocatalysts.

\section{Introduction}

The aldol reaction is one of the most important reactions for the convergent generation of $\mathrm{C}-\mathrm{C}$ bonds. ${ }^{[1]}$ This transformation is operative in biochemical processes, type I and II aldolases being the main representative enzymes. ${ }^{[2]}$ Although it has been known since 1971-1974 that L-proline (L-Pro) can catalyze intramolecular aldol reactions, ${ }^{[3,4]}$ the 2000 report by Barbas and List ${ }^{[5,6]}$ of intermolecular aldol reactions catalyzed by L-Pro prompted an impressive upsurge of work on this reaction. ${ }^{[7]}$ The term organocatalysis, explicitly mentioned by MacMillan ${ }^{[8]}$ in a paper also published in 2000, contributed to placing these reactions in a well-defined and readily identifiable category. Thus, dif-

[a] Departamento de Química Orgánica I / Kimika Organikoa I Saila, and Centro de Innovación en Quíimica Avanzada (ORFEO-CINQA), Facultad de Química / Kimika Fakultatea, Universidad del País Vasco / Euskal Herriko Unibertsitatea (UPV/EHU), and Donostia International Physics Center (DIPC),

P. K. 1072, 20018 San Sebastián - Donostia, Spain E-mail: fp.cossio@ehu.es http://www.ehu.eus/eu/web/qbmm/hasiera

[b] IKERBASQUE, Basque Foundation for Science, 48013 Bilbao, Spain

[c] SGIker NMR Facility, 20018 San Sebastián - Donostia, Spain

[d] Departamento de Química Orgánica e Instituto de 7 esis Orgánica (ISO), and Centro de Innovación en Quí Avanzada (ORFEO-CINQA). Facultad de Ciencias, Universidad de Alicante, 03080 Alicante, Spain

[e] Departamento de Química Orgánica, Instituto de Síntesis Química y Catálisis Homogénea (ISQCH), CSIC-Universidad de Zaragoza,

50009 Zaragoza, Spain

Supporting information for this article is available on the WWW under http://dx.doi.org/10.1002/ejoc.201500160. ferent organocatalysts have been tested in aldol reactions; ${ }^{[9]}$ they include natural amino acids ${ }^{[10]}$ such as histidine, ${ }^{[11]}$ serine, ${ }^{[12]}$ threonine, ${ }^{[12,13]}$ tryptophan, ${ }^{[12,14]}$ alanine, ${ }^{[15]}$ and isoleucine. ${ }^{[16]}$ Of these natural amino acids, L-Pro (and its derivatives) has emerged as the most widely used organocatalysts for the aldol reaction. Trost and Brindle, ${ }^{[17]}$ in their comprehensive review published in 2010, reported around $45 \mathrm{~L}$-Pro derivatives that are able to catalyze aldol reactions. It is relevant to note that in all these cases the stereochemistry of the major aldol adducts was found to be the same: namely, that associated with the $\left(2 S, 1^{\prime} R\right)$ configuration in the new chiral carbon atoms (Scheme 1).

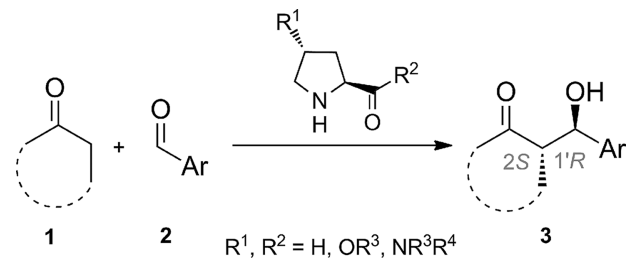

Scheme 1. Stereochemical outcome observed in aldol reactions catalyzed by L-Pro derivatives.

The mechanism and origin of the stereocontrol of L-Procatalyzed aldol reactions have been studied both experimentally ${ }^{[18]}$ and computationally. ${ }^{[19]}$ The generally accepted mechanism is shown in Figure 1. According to this catalytic cycle, the first stage of the reaction involves the formation of enamine intermediates of type INT1, a process that can be promoted by acidic protons present in the starting amino acid or in the reaction medium. ${ }^{[20]}$ These intermediates have 
been characterized spectroscopically ${ }^{[21]}$ and by X-ray diffraction analysis. ${ }^{[2]}$

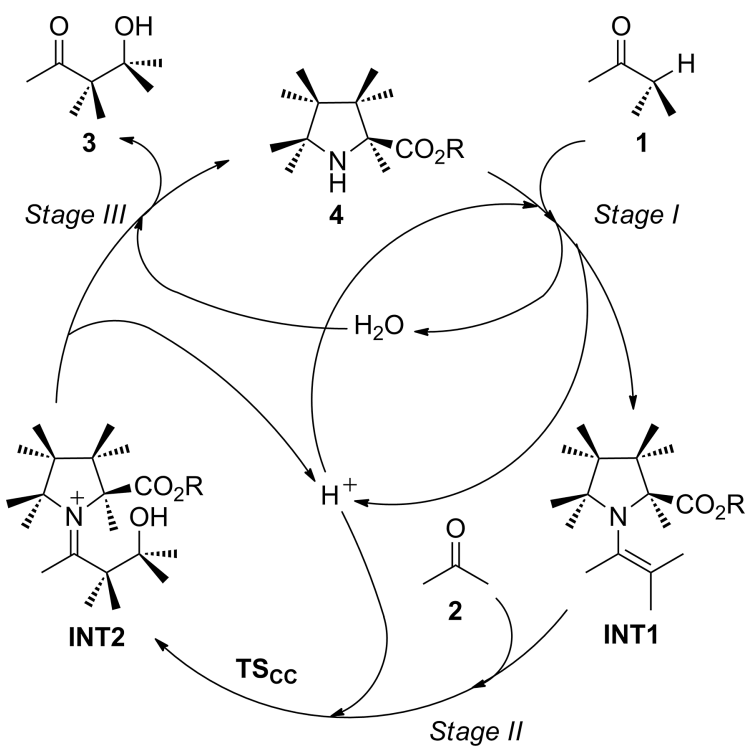

Figure 1. General catalytic cycle of aldol reactions catalyzed by Lproline derivatives. Unless otherwise indicated, the possible substituents at the different positions have not been specified.

Formation of the new $\mathrm{C}-\mathrm{C}$ bond takes place during the second stage of the reaction (Figure 1), giving rise to iminium intermediates of type INT2. Once again, when L-Pro is used, the carboxy group provides the proton required to enhance the electrophilicity of a carbonyl compound $\mathbf{2}$. The overall arrangement of the transition structures of type TScc associated with this stage, usually referred to as the Houk-List model, ${ }^{[23]}$ shows a chair-like shape in which the Zimmerman-Traxler ${ }^{[24]}$ arrangement is extended to form a cyclic transition structure involving the carboxy group of the organocatalyst. Finally, the iminium intermediate of type INT2 is hydrolyzed to release the aldol $\mathbf{3}$ and the organocatalyst $\mathbf{4}$, thus completing the catalytic cycle (Figure 1). It is important to note, however, that the HoukList model relies on the presence of an acidic residue in the organocatalyst. When other functional groups such as ester, amido, amino, etc. ${ }^{[7 \mathrm{~b}, 7 \mathrm{~g}]} \boldsymbol{\square}((<=$ Author: change ref $7 \mathrm{f}-$ $>7 \mathrm{~g}$ correct??)) $\square$ are present instead of the carboxylic acid, acidic additives or protic substituents are usually required. Although the origins of stereocontrol in these cases are far from being fully understood, computational studies on selected systems ${ }^{[19 a]}$ have shown that transition structures closely related to the Houk-List model are compatible with the observed stereochemical outcomes.

According to this conceptual framework, the stereochemistry of the reaction is determined by the L configuration of the amino acid and the distal (anti) conformation of the enamine double bond with respect to the carboxy group. ${ }^{[23]}$ Therefore, it is not surprising that L-Pro derivatives yield the same enantiomers in reactions of this kind.
To the best of our knowledge, no structure-activity relationship studies on the organocatalytic properties of synthetic densely substituted L-proline derivatives have been reported to date. These compounds show great promise in the field and are easily accessible because the 2-alkoxycarbonylpyrrolidine scaffold can be formed in a single step through [3+2] cycloaddition between readily available $\pi$-deficient alkenes and azomethine ylides generated in situ. ${ }^{[25]}$ Recently, we have reported new ferrocenyl-containing proline catalysts that are able to yield both endo- and exo-L4-nitroproline esters with high enantiocontrol. ${ }^{[26]}$ We also showed that the exo cycloadducts are able to catalyze the aldol reaction efficiently. ${ }^{[26]}$ Here we compare the performances of L-4-nitroproline esters and acids featuring different substitution patterns and stereochemical configurations as organocatalysts in the aldol reaction. The ultimate goal of this research is to provide design criteria for organocatalysts based on unnatural proline esters obtained directly through fully stereocontrolled [3+2] cycloadditions.

\section{Results and Discussion}

\section{Preparation of Unnatural Proline Organocatalysts}

We prepared different L-4-nitroproline esters through asymmetric 1,3-dipolar cycloaddition reactions between different dipolarophiles and azomethine ylides formed in situ from the corresponding imines (Scheme 2 and Scheme 3). The reactions were catalyzed by enantiopure 5ferrocenyl-4-nitroprolines L-5a and D-5b or phosphoramidite $\left(S_{a}-R, R\right)-6$, previously developed and tested as catalysts for reactions of this type by the San Sebastian-Donostia ${ }^{[26]}$ and Alicante ${ }^{[27]}$ groups, respectively (Scheme 2).
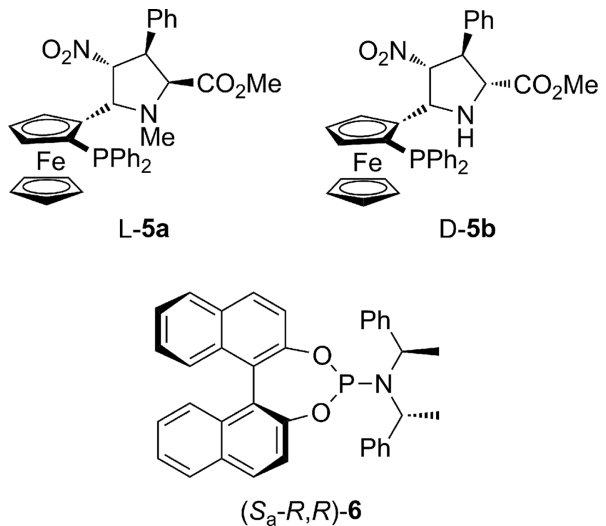

Scheme 2. Catalysts used in the synthesis of unnatural L-prolines 4.

By use of glycine iminoesters $\mathbf{7 a - f}$ as precursors of azomethine ylides, nitroalkenes $\mathbf{8 a - c}$ as dipolarophiles, and L5a, D-5b, or $\left(S_{a}-R, R\right)-\mathbf{6}$ as catalysts, endo- and exo-L-4-nitro- 


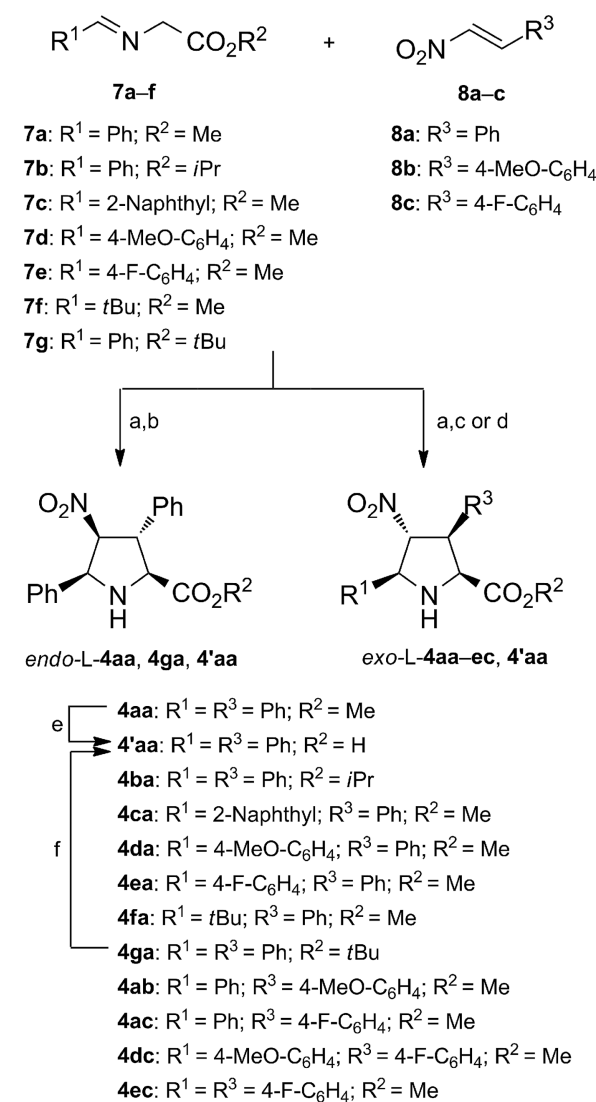

Scheme 3. Synthesis of unnatural L-proline derivatives endo-L-4aa and exo-L-4aa-ec. Reagents and conditions: (a) $\mathrm{Cu}\left(\mathrm{CH}_{3} \mathrm{CN}\right)_{4} \mathrm{PF}_{6}$ (3 mol- $\%$ ), NEt 3 ( 5 mol- $\%$ ), THF; (b) L-5a $(3$ mol- $\%),-60{ }^{\circ} \mathrm{C}$; (c) D5b $(3 \mathrm{~mol}-\%),-20{ }^{\circ} \mathrm{C}$; (d) $\mathrm{Cu}(\mathrm{OTf})_{2},(5 \mathrm{~mol}-\%),\left(S_{\mathrm{a}}-R, R\right)-6$ ( 5 mol$\%), \mathrm{NEt}_{3}(5 \mathrm{~mol}-\%)$, toluene, r.t. (e) $\mathrm{NaOH}, \mathrm{H}_{2} \mathrm{O} /$ acetone, r.t. (f) TFA, $\mathrm{CH}_{2} \mathrm{Cl}_{2}$, r.t.

proline esters 4aa-ec were obtained (Scheme 3). In all cases, good yields and high optical purities were achieved. ${ }^{[26]}$ When $\mathrm{R}^{1}$ was a secondary alkyl group, such as cyclohexyl, the desired cycloadducts were not formed. However, in the case of $\mathrm{R}^{1}=$ tert-butyl, exo-L-4fa was obtained with high enantiomeric excess. When $N$-methylmaleimide (9d) was used as the dipolarophile in the presence of $\mathbf{D}-\mathbf{5 b}$ as a catalyst, endo-L-4ad was isolated (Scheme 4). Unfortunately, imine $\mathbf{7 h}$, derived from L-phenylalanine methyl ester, gave poor enantiomeric excesses in the presence of either L-5a or D5b. However, a catalytic amount of phosphoramidite $\left(S_{a^{-}}\right.$ $R, R)-6$ promoted the formation of exo-L-4ha as the sole enantiomer (Scheme 4). ${ }^{[27]}$ This catalyst was also effective in the preparation of exo-L-4ia from imine 7i. Therefore, our previously reported methodologies, ${ }^{[26,27]}$ provided a convenient route to cycloadducts endo- and exo-L-4aa-ga as enantiopure compounds in high yields from easily or commercially available reactants $\left(7,{ }^{[28]} \mathbf{8}\right.$, and 9$)$ in the presence of readily accessible catalysts (Scheme 2). Such cycloadducts were isolated in useful quantities for subsequent evaluation as organocatalysts.

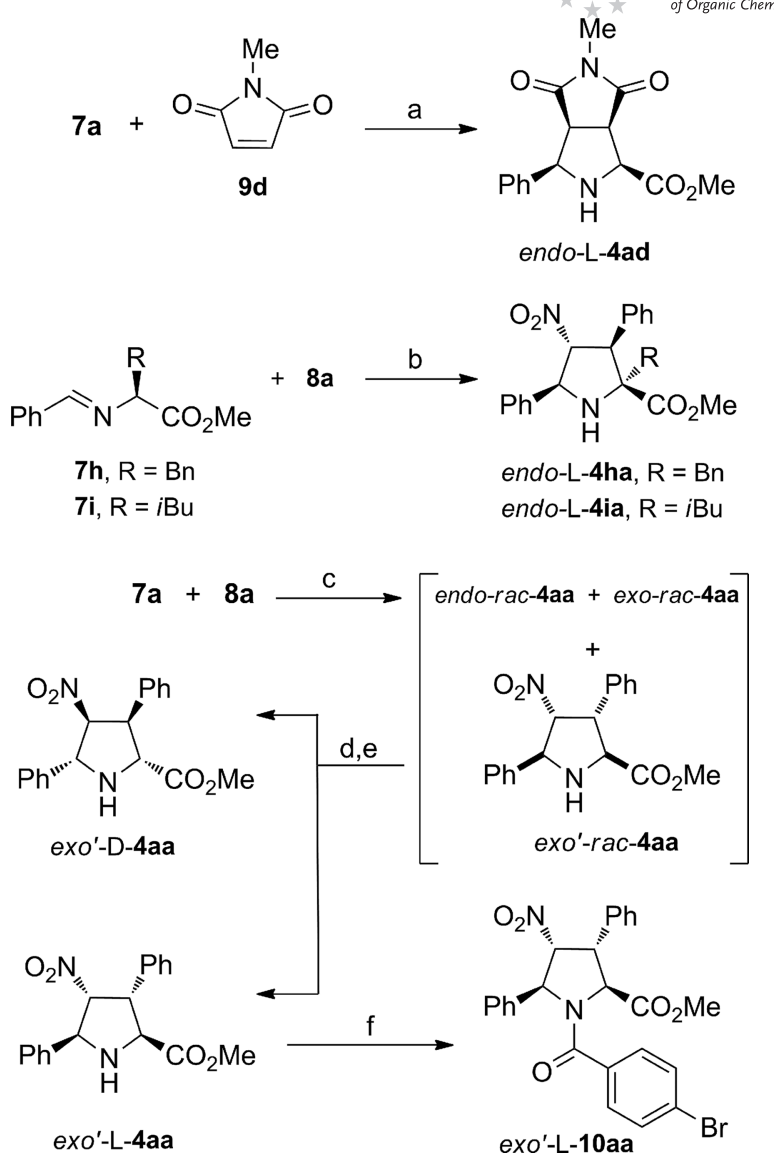

Scheme 4. Synthesis of unnatural L-proline esters endo-L-4ad, exoL-4ha, exo-L-4ia, and exo'-L-4aa. Reagents and conditions: (a) $\mathrm{Cu}\left(\mathrm{CH}_{3} \mathrm{CN}\right)_{4} \mathrm{PF}_{6}(3 \mathrm{~mol}-\%)$, D-5b $(3 \mathrm{~mol}-\%), \mathrm{NEt}_{3}(3 \mathrm{~mol}-\%)$, THF, r.t.; (b) $\mathrm{Cu}(\mathrm{OTf})_{2},(5 \mathrm{~mol}-\%),\left(S_{\mathrm{a}}-R, R\right)-6$ (5 mol- $\left.\%\right), \mathrm{NEt}_{3}$ $(5 \mathrm{~mol}-\%)$, toluene, r.t.; (c) AgOAc $\left(15 \mathrm{~mol}^{-} \%\right)$, $\mathrm{NEt}_{3}(15 \mathrm{~mol}-\%)$ $\mathrm{CH}_{3} \mathrm{CN}$, r.t.; (d) column chromatography on silica gel to isolate exo'-rac-4aa; (e) preparative HPLC resolution on a chiral column (Chiralpak ${ }^{\circledR}$ IB); (f) 4-bromobenzoyl chloride (2.0 equiv.), DIPEA (2.6 equiv.), $\mathrm{CHCl}_{3}$, r.t.

With the aim of further increasing the stereochemical diversity of the L-4-nitroproline cycloadducts for testing as organocatalysts, the $[3+2]$ cycloaddition reaction starting from imine $7 \mathbf{a}$ and $\beta$-nitrostyrene (8a) was carried out in the presence of silver acetate and triethylamine. In this case, a mixture of racemic endo-, exo-, and exo'-rac-4aa cycloadducts was obtained (Scheme 4), from which the minor isomer exo'-rac-4aa was separated by column chromatography on silica gel. This racemic compound was then subjected to preparative resolution by HPLC with a chiral column, which allowed the isolation of exo'-L-4aa and exo'-D-4aa in optically pure form (see the Supporting Information). Assignment of the absolute configurations of the resolved enantiomers was carried out by transformation of the firsteluting enantiomer (exo'-L-4aa) into the corresponding $N$ (4-bromobenzoyl) derivative exo'-L-10aa (Scheme 4) and resolution of the crystalline structure of this compound by X-ray diffraction analysis. ${ }^{[29]}$ 


\section{Kinetic Studies}

In order to assess the organocatalytic activity of the synthesized unnatural proline esters $\mathrm{L}-\mathbf{4}$, we chose as a case study the aldol reaction between cyclohexanone (1a) and pentafluorobenzaldehyde (2a). In principle, four isomeric adducts 3aa can be expected for this reaction (Scheme 5).

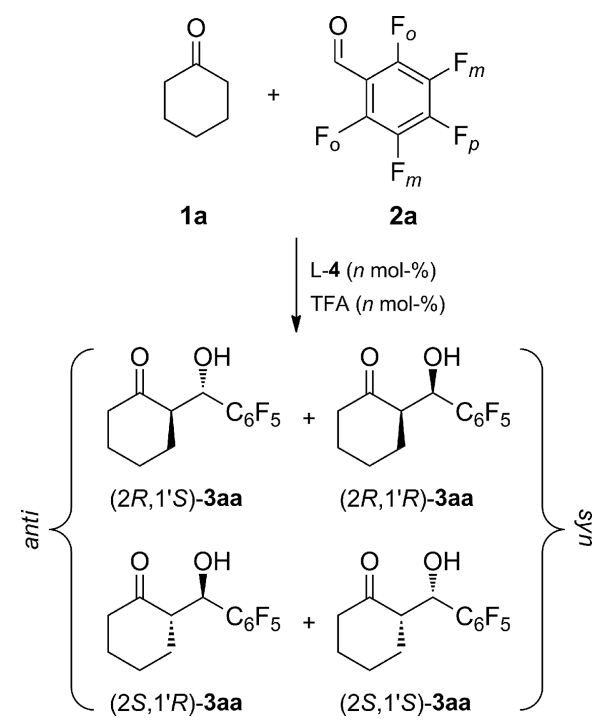

Scheme 5. Model aldol reaction to assess the organocatalytic activity of cycloadducts 4 . Descriptors $o, m$ and $p$ denote ortho, meta and para positions with respect to the carbaldehyde group.

Preliminary studies ${ }^{[26]}$ showed that $\mathbf{2 a}$ is quite electrophilic, and therefore the progress of the aldol reaction in the presence of different organocatalysts can be monitored in relatively short reaction times. In addition, the presence of fluorine atoms in ortho, meta, and para positions with respect to the carbaldehyde group (Figure 2) allows monitoring of the evolution of the reaction mixtures by ${ }^{19} \mathrm{~F}$ NMR spectroscopy. The different signals were assigned by measuring the ${ }^{3} J_{\mathrm{F}, \mathrm{F}}$ and ${ }^{4} J_{\mathrm{F}, \mathrm{F}}$ coupling constants (see the Supporting Information). Figure 2 (A) shows the spectra registered for the reaction between $\mathbf{1 a}$ and $\mathbf{2 a}$ in the presence of exo-L-4aa with a catalytic load of $30 \mathrm{~mol}-\%$ at $298 \mathrm{~K}$. Together with the consumption of the starting aldehyde $\mathbf{2 a}$, formation of the major and minor adducts anti3aa and syn-3aa, respectively, can be observed. Moreover, transient formation of iminium intermediates INT2a (Scheme 1) can be detected under these conditions (Figure 2).

In order to monitor the presence of enamine intermediates of type INT1 (Scheme 1) by this method, at least one fluorine atom must be present in the catalyst. We therefore studied the same reaction in the presence of exo-L-4ea (Figure 3). In this case, aside from the ensemble of signals between -140 and -165 ppm associated with the $\mathrm{C}_{6} \mathrm{~F}_{5}$ moiety (Figure 2), both enamine intermediates INT1b and INT2b were detected between $-113 \mathrm{ppm}$ and $-115 \mathrm{ppm}$, together
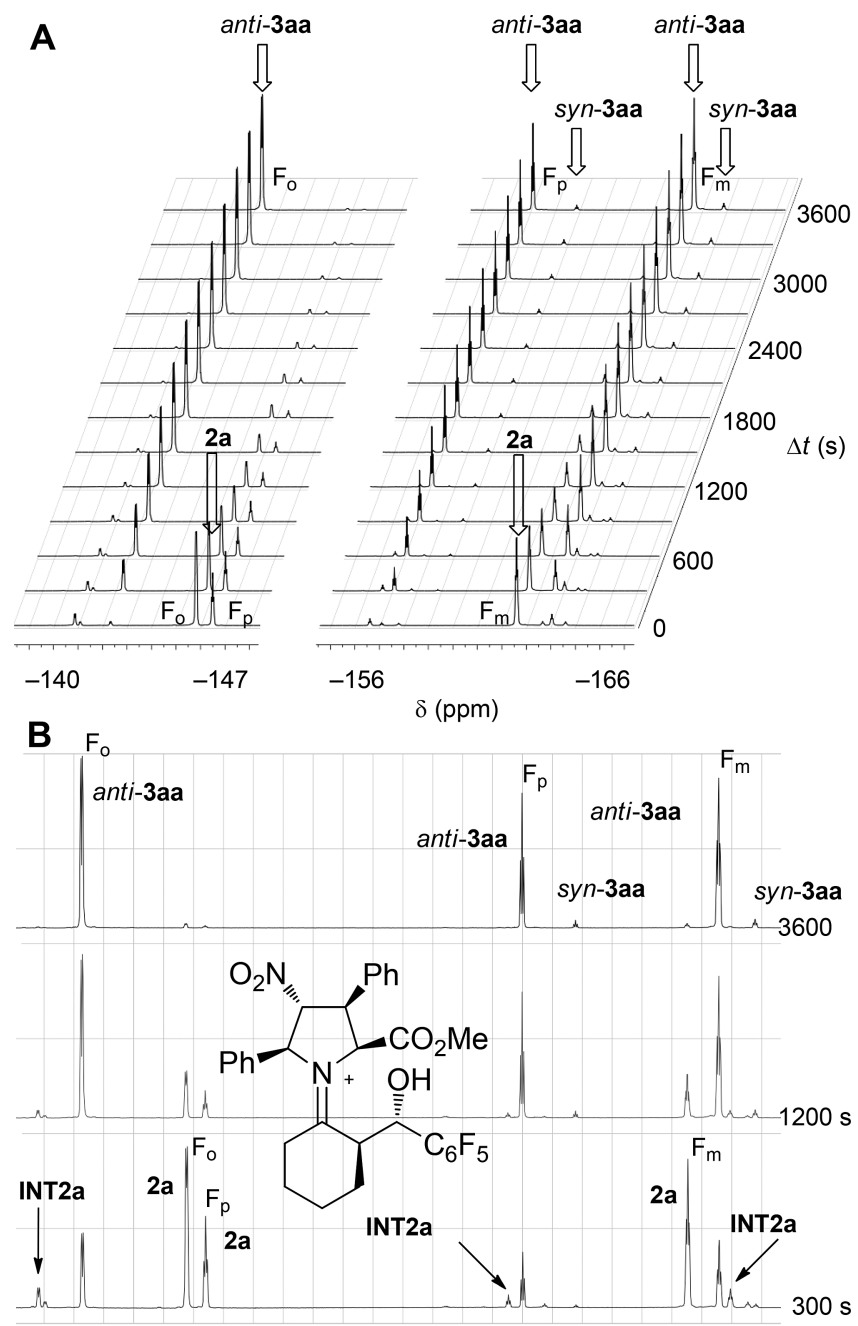

$-145$

$\delta(\mathrm{ppm})$

$-155$

$-165$

Figure 2. (A) ${ }^{19} \mathrm{~F}$ NMR spectra obtained for the aldol reaction between 1a and $\mathbf{2 a}$ to form adducts 3aa, catalyzed by exo-L-4aa. The hollow arrows show the decay of the signals corresponding to $\mathbf{2 a}$. These decays were used to estimate the kinetic constants. (B) Three selected spectra showing the evolution of reactants, products, and iminium intermediate INT2a (Figure 1).

with the broad signal corresponding to exo-L-4ea (Figure 3). These observations are compatible with the catalytic cycle depicted in Figure 1, because both enamine and iminium aldol intermediates were detected, the latter being more persistent. This suggests that, most likely, the hydrolytic step (stage III, Figure 1) is kinetically slower than the formation of the nucleophilic enamine.

With this information, we undertook the determination of the kinetic constants associated with the $\mathbf{1 a}+\mathbf{2} \mathbf{a} \rightarrow \mathbf{3}$ aa reaction in the presence of different organocatalysts. Because the previously discussed ${ }^{19} \mathrm{~F}$ NMR studies had suggested a kinetically complex profile, we decided to work under pseudo-first order conditions, with a 1a/2a ratio of 60:1. The apparent reaction rates were measured according to Equation (1). 


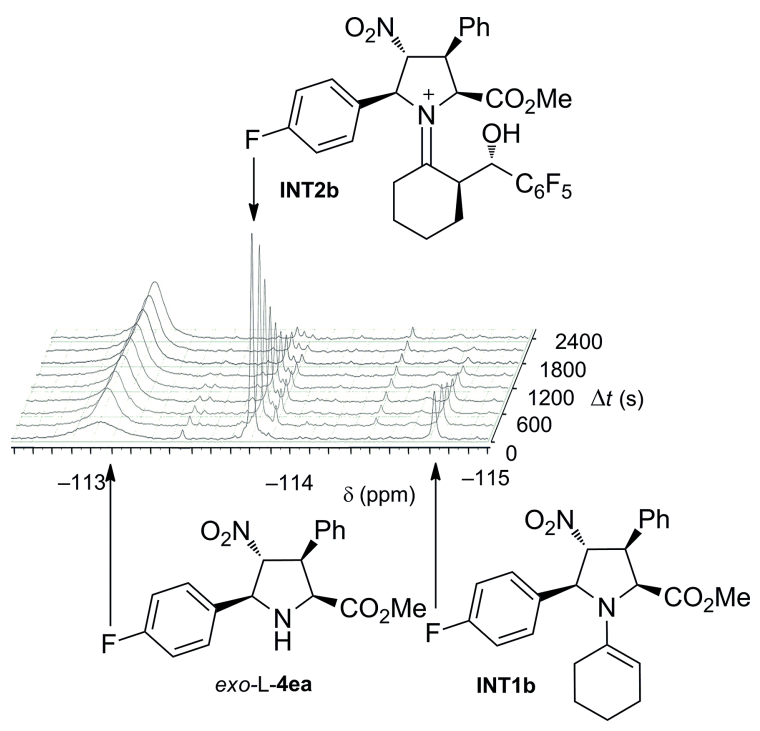

Figure 3. ${ }^{19} \mathrm{~F}$ NMR spectra associated with the aldol reaction between 1a and 2a catalyzed by exo-L-4ea, showing the evolution of the catalyst, enamine intermediate INT1b, and iminium intermediate INT2b.

rate $=-\frac{d[2 a]}{d t} \approx k_{o b s}[2 a]$

As internal reference we used the signal corresponding to trifluoroacetic acid (TFA). For each signal associated with ortho, meta, and para fluorine atoms of $\mathbf{2 a}$, we monitored the decay of the corresponding integrals (Figure 2, A) by means of Equation (2)

$\ln \left(\frac{I_{t}^{i}}{I_{t}^{T F A}}\right)-\ln \left(\frac{I_{0}^{i}}{I_{o}^{T F A}}\right)=-k_{o b s} t$

where $I_{t}^{i}$ and $I_{0}^{i}$ are the instant and initial integrals, respectively, of the $i$-fluorine atom of 2a. The experimental measurements were averaged for the three sets of signals associated with the ortho, meta, and para fluorine atoms of $\mathbf{2 a}$. Figure 4 (A) shows the conversion of 1a and $\mathbf{2 a}$ into 3aa in the presence of organocatalysts exo-L-4aa, endo-L-4aa, and exo'-L-4aa. Figure 4 (B) shows the linear plot obtained after application of Equation (2). Similar excellent correlations were obtained in the remaining cases, thus showing pseudofirst order behavior of the studied reactions (see the Supporting Information). The kinetic constants calculated from treatment of NMR spectroscopic data by application of Equation (2) are collected in Table 1.

Our results indicate that, for the different L-4aa stereoisomers tested, the catalytic activity order is exo $>$ endo $>>$ exo'. Therefore, although the configurations of the $C 2$ and idine ring are identical in the three cases, the stereochemistry at the distal $C 3$ and $C 4$ atoms has a considerable effect on the rate of the aldol reaction. In particular, the relative cis configuration of the phenyl and nitro groups in exo' $-\mathrm{L}-$

A

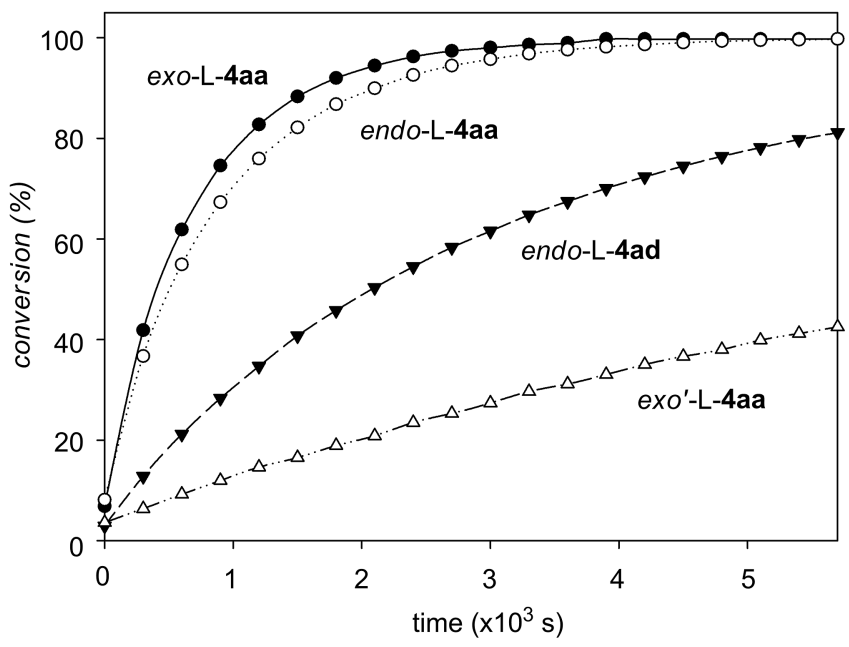

B

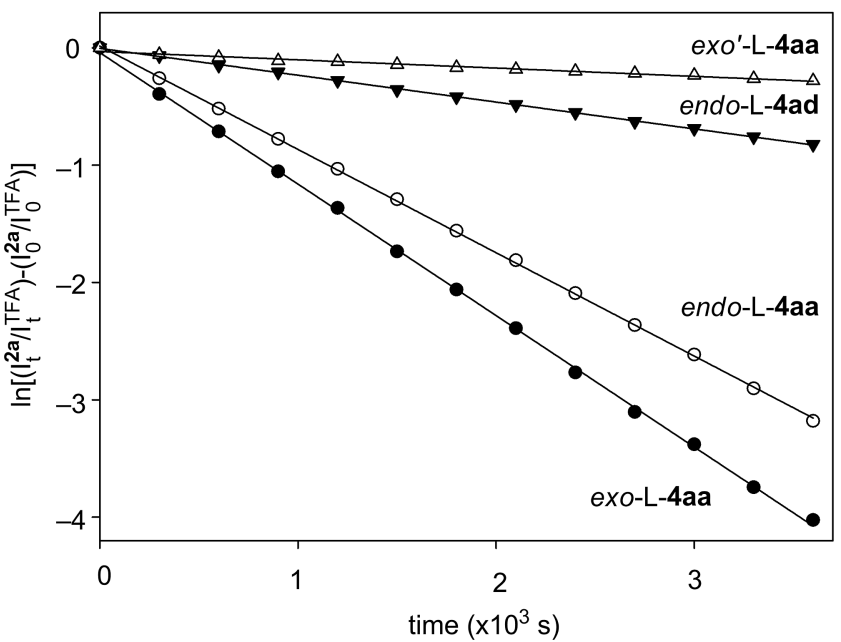

Figure 4. (A) Levels of conversion over time associated with the 1a $+\mathbf{2} \mathbf{a} \rightarrow$ 3aa transformation in the presence of organocatalysts exoL-4aa, endo-L-4aa, exo'-L-4aa, and endo-L-4ad. All reactions were monitored under pseudo-first order conditions at $25{ }^{\circ} \mathrm{C}$ by ${ }^{19} \mathrm{~F}$ NMR (see text). (B) Pseudo-first order linear plots obtained for the organocatalyzed reactions shown in (A). These plots were used to determine $k_{\text {obs }}$ (see text).

4aa results in a significantly lower kinetic constant (Table 1, Entry 4).

In order to confirm this result with an endo-cycloadduct possessing cis substituents at $C 3$ and $C 4$, we measured the $k_{\text {obs }}$ value for endo-L-4ad and also observed a relatively low kinetic constant (Table 1, Entry 5). Therefore, we conclude that a cis relationship between the substituents at $C 3$ and $C 4$ results in a lower organocatalytic activity. It is also noteworthy that exo-L-4aa retains a significantly high $k_{\text {obs }}$ value with a catalytic load of 5 mol-\% (Table 1, Entry 2).

In order to assess the role of TFA in general or specific co-catalytic schemes ${ }^{[30]}$ we measured the values of $k_{\text {obs }}$ for the $\mathbf{1 a}+\mathbf{2} \mathbf{a} \rightarrow \mathbf{3 a a}$ reaction catalyzed by exo-L-4aa in the presence of different TFA concentrations. The results are collected in Table 2, in which we have included the $k_{\text {obs }}$ value in the absence of acid. This value (Table 2, Entry 1) 
Table 1. Measured catalytic constants $\left(k_{\text {obs }}\right)$ for cycloadducts exo$\mathrm{L}-4 \mathbf{a a}$, endo-L-4aa, exo'-L-4aa, and endo-L-4ad in the $\mathbf{1 a}+\mathbf{2 a} \rightarrow \mathbf{3 a a}$ reaction. ${ }^{[\mathrm{a}, \mathrm{b}]}$

Entry Cat.

[a] Pseudo-first order constants calculated by application of Equation (2) with a $\mathbf{1 a} / \mathbf{2 a}$ ratio of $60: 1$. [b] All reactions were monitored by ${ }^{19} \mathrm{~F}$ NMR at $25^{\circ} \mathrm{C}$.

was found to be two to three orders of magnitude lower than those observed when TFA was added (Table 2, Entries 4-11). Other carboxylic acids such as acetic acid and 4-nitrobenzoic acid promoted smaller enhancements of the $k_{\text {obs }}$ values. Therefore, TFA proved to be a convenient acidic additive for this reaction. In addition, according to our experiments with variable concentrations of TFA, a roughly linear behavior of $k_{\mathrm{obs}}$ with respect to [TFA] is observed for acid concentrations within the catalytic range (i.e., close to

Table 2. Pseudo-first order experimentally measured ${ }^{[\mathrm{a}, \mathrm{b}]}\left(k_{\mathrm{obs}}\right)$ and calculated $^{[\mathrm{c}]}\left(k_{\text {calc }}\right)$ kinetic constants measured for the $\mathbf{1 a}+\mathbf{2} \mathbf{a} \rightarrow \mathbf{3} \mathbf{a} a$ reaction catalyzed by exo-L-4aa with different acids and concentrations.

\begin{tabular}{llll}
\hline Entry & Acid & Mol- $\%$ & $k_{\text {obs }}\left(\times 10^{-4} \mathrm{~s}^{-1}\right)$ \\
\hline 1 & none & 0 & $0.0429( \pm 0.0004)$ \\
2 & AcOH & 30 & $0.551( \pm 0.016)$ \\
3 & PNB $^{[c]}$ & 30 & $0.388( \pm 0.003)$ \\
4 & TFA & 15 & $6.37( \pm 0.14)$ \\
5 & TFA & 20 & $8.60( \pm 0.34)$ \\
6 & TFA & 25 & $10.00( \pm 0.29)$ \\
7 & TFA & 30 & $11.29( \pm 0.30)$ \\
8 & TFA & 50 & $15.73( \pm 0.35)$ \\
9 & TFA & 60 & $18.44( \pm 0.14)$ \\
10 & TFA & 75 & $21.88( \pm 0.19)$ \\
11 & TFA & 100 & $25.53( \pm 0.76)$ \\
12 & TFA & 150 & $26.75( \pm 0.06)$ \\
\hline
\end{tabular}

[a] Pseudo-first order constants calculated by application of Equation (2) with a $\mathbf{1 a} / \mathbf{2 a}$ ratio of $60: 1$. [b] All reactions were monitored by ${ }^{19} \mathrm{~F}$ NMR at $25^{\circ} \mathrm{C}$. [c] PNB: $p$-nitrobenzoic acid.

2a). For higher values, the measured $k_{\text {obs }}$ values evolve towards a saturation profile.

We reasoned that the behavior reported in Table 2 could be described by Equation (3).

$k_{\mathrm{obs}}=k_{0}+\frac{A[T F A]}{B+[T F A]}$

In Equation (3), $k_{0}$ is the $k_{\text {obs }}$ value for [TFA] $=0$ (Table 2, Entry 1), and A and B are two constants that can be determined from the experimental data reported in Table 2. For low values of [TFA] (i.e., for [TFA] $<<B$ ), Equation (3) can be approximated as $k_{\mathrm{obs}}-k_{0} \approx(A / B)$ [TFA], thus resulting in linear behavior. On the other hand, if [TFA] $>B$, then Equation (3) approaches to a zeroslope profile in the form $k_{\text {obs }}-k_{0} \approx A$, which would be associated with a maximum $k_{\mathrm{obs}}-k_{0}$ value.

A double reciprocal treatment ${ }^{[31]}$ of the data in Table 2 revealed a good linear regression $\left(r^{2}=0.996\right)$ with $A=$ $47.40 \times 10^{-4}$ and $B=95.10$, as can be seen in Figure 5. This result confirms that the hypothesis proposed in Equation (3) is reasonable for the concentrations tested in our experiments. A possible interpretation of these results is that, despite the complex, multistep mechanism required for the catalysis of these aldol reactions, at catalytic concentrations the proton transfer to the oxygen atom of the aldehyde is involved in the rate-limiting step. At higher concentrations of TFA, protonation of the aldehyde occurs prior to the step associated with the formation of the $\mathrm{C}-\mathrm{C}$ bond, the protonated aldehyde being the effective electrophile.

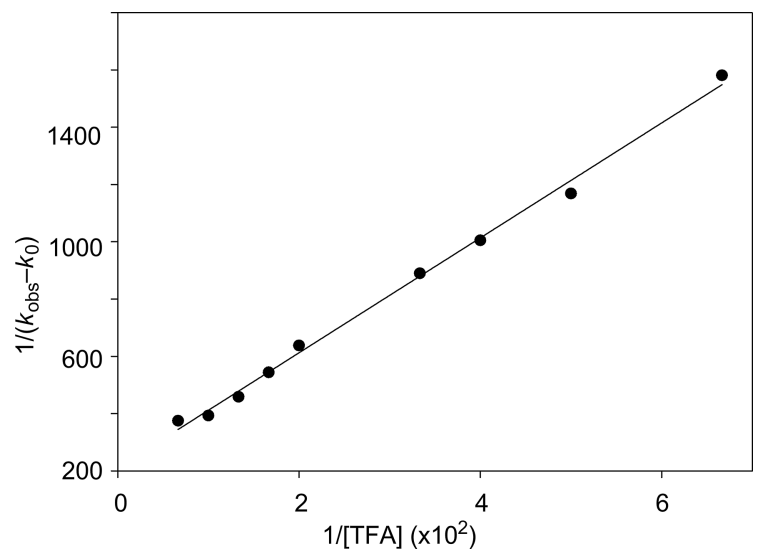

Figure 5. Double reciprocal treatment of the pseudo-first order constants $\left(k_{\mathrm{obs}}\right)$ reported in Table 2.

Kinetic isotope effects (KIEs) were measured for the 1a $+\mathbf{2 a} \rightarrow \mathbf{3 a a}$ reaction catalyzed by exo-L-4aa. The results are collected in Table 3 . When the reaction was performed in the presence of $\alpha, \alpha, \alpha^{\prime}, \alpha^{\prime}$-tetradeuterated cyclohexanone 1a$d_{4}$, a KIE of 2.68 was observed (Table 3 , Entry 1 ). This value is between the KIE reported for the nornicotin-catalyzed aldol reaction between acetone and 4-nitrobenzaldehyde, for which Janda et al. ${ }^{[32]}$ measured a KIE of 3.0 in the presence of $\mathrm{D}_{2} \mathrm{O}$, and the $\mathrm{KIE} \approx 2$ found by Blackmond et al. ${ }^{[33]}$ for the L-Pro-catalyzed reaction between $\left[\mathrm{D}_{6}\right]$ acetone and 3-chlorobenzaldehyde. 
Table 3. Kinetic isotope experiments conducted ${ }^{[a]}$ for the $\mathbf{1 a}+$ $\mathbf{2 a} \rightarrow \mathbf{3 a a}$ reaction catalyzed by cycloadduct exo-L-4aa.

\begin{tabular}{lllllll}
$(30 \mathrm{~mol}-\%)$ \\
Entry & $\mathrm{X}$ & $\mathrm{Y}$ & $\mathrm{Z}$ & $k_{\text {obs }}\left(\times 10^{-4} \mathrm{~s}^{-1}\right)$ & $k_{\mathrm{H}} / k_{\mathrm{D}}$ \\
\hline 1 & $\mathrm{D}$ & $\mathrm{H}$ & $\mathrm{H}$ & $4.21( \pm 0.29)$ & $2.68( \pm 0.20)$ \\
2 & $\mathrm{H}$ & $\mathrm{D}$ & $\mathrm{H}$ & $7.61( \pm 0.22)$ & $1.48( \pm 0.06)$ \\
3 & $\mathrm{H}$ & $\mathrm{H}$ & $\mathrm{D}$ & $11.59( \pm 0.22)$ & $0.97( \pm 0.03)$ \\
4 & $\mathrm{H}$ & $\mathrm{D}$ & $\mathrm{D}$ & $7.36( \pm 0.51)$ & $1.53( \pm 0.11)$ \\
5 & $\mathrm{D}$ & $\mathrm{D}$ & $\mathrm{D}$ & $3.16( \pm 0.24)$ & $3.57( \pm 0.29)$ \\
\hline
\end{tabular}

[a] All reactions were conducted in neat $\mathbf{1 a}$ at $25^{\circ} \mathrm{C}$ with a $\mathbf{1 a} / \mathbf{2 a}$ ratio of 60:1. Reference value: $k_{\mathrm{H}}=11.29 \times 10^{-4}( \pm 0.30)$ (see Table 1). [b] Errors were calculated from standard deviations of the rate constants according to ref. ${ }^{[34]}$

In the presence of $N$-deuterated exo-L-4aa, a significant normal KIE was detected (Table 3, Entry 2). When the acidic position of TFA was deuterated (Table 3, Entry 3) we were unable to measure any noticeable KIE within the experimental error. In line with these two results, deuteration of the acidic positions of both exo-L-4aa and TFA resulted in a normal KIE similar to that found when only the $\mathrm{NH}$-site of exo-L-4aa was deuterated (Table 3, Entries 2 and 4). Finally, deuteration at the four $\alpha$-positions of $1 \mathrm{a}$ and of the acidic sites in exo-L-4aa and TFA resulted in a KIE of 3.57 (Table 3, Entry 5), a value larger than that measured in the presence of $\mathbf{1 a}-d_{4}$.

In summary, from the experiments reported in Table 3 we conclude that the observed KIE for the deuterated nucleophile is the outcome of a tradeoff between the large normal primary KIE associated with the formation of the enamine intermediate (Figure 1, stage I), the inverse secondary KIE expected for the $\mathrm{C}-\mathrm{C}$ bond-forming step (Figure 1, stage II), and the normal primary KIE associated with the hydrolysis of the iminium aldol adduct (Figure 1, stage III), in the presence of enolization equilibria under general acid catalysis conditions within the $30 \mathrm{~mol}-\%$ range

316 (see Table 2). We can also conclude that stage II, associated with the formation of the $\mathrm{C}-\mathrm{C}$ bond and hence with the stereocontrol of the aldol reaction, cannot be considered the rate-limiting step.

The diastereo- and enantioselectivities observed for the $\mathbf{a}+\mathbf{2} \mathbf{a} \rightarrow \mathbf{3}$ aa reaction catalyzed by the three $\mathrm{L}-\mathbf{4 a a}$ cycloadducts were also measured, and the results are included in Table 4. In the case of exo-L-4aa, an excellent anti selectivity was observed. A catalytic load of $5 \mathrm{~mol}-\%$ was not detrimental in terms of stereocontrol and chemical yield (Table 4, Entries 1 and 2). In addition, the enantiomeric excess (ee) was slightly better at $-15^{\circ} \mathrm{C}$ (Table 4, Entry 3 ). When acetic acid and 4-nitrobenzoic acids were used as additives in the presence of exo-L-4aa (Table 4, Entries 4 and
5), the measured ee values were slightly lower than those obtained with TFA, thus confirming the superior performance of this last additive, not only in terms of kinetic acceleration (vide supra), but also in terms of stereocontrol. Cycloadducts endo-L-4aa and endo-L-4ad gave good syn/anti diastereocontrol and chemical yields (Table 4, Entries 6, 7, and 9). Surprisingly, the sense of chiral induction of endoL-4aa, exo'-L-4aa, and endo-L-4ad was found to be the opposite of that observed for exo-L-4aa. This unexpected result is discussed later on. Finally, it is worth noting that exo'-L-4aa and endo-L-4ad, with cis substituents at $C 3$ and $C 4$, give poor enantiocontrol, the former also showing a low syn/anti diastereoselectivity (Table 4, Entries 8 and 9). Therefore, these two compounds are not convenient in terms of organocatalytic activity (vide supra) and stereocontrol.

Table 4. Stereocontrol and chemical yields observed ${ }^{[a]}$ in the $\mathbf{1 a}+$ $\mathbf{2 a} \rightarrow \mathbf{3 a a}$ reaction catalyzed by cycloadducts exo-L-4aa, endo-L-4aa, exo $o^{\prime}-\mathrm{L}-4 \mathbf{a a}$, and endo-L-4ad in the presence of TFA $(30 \mathrm{~mol}-\%)$

\begin{tabular}{llccccc}
\hline Entry & Cat. & $\begin{array}{c}T \\
{\left[{ }^{\circ} \mathrm{C}\right]}\end{array}$ & $\begin{array}{c}\text { Cat. load } \\
{[\text { mol- } \%]}\end{array}$ & antilsyn $^{[\mathrm{b}]}$ & $\begin{array}{c}\text { Yield }^{[\mathrm{c}]} \\
{[\%]}\end{array}$ & $\begin{array}{c}e^{[\mathrm{d}]} \\
{[\%]}\end{array}$ \\
\hline $1^{[\mathrm{e}]}$ & exo-L-4aa & 25 & 30 & $95: 05$ & 73 & $89^{[\mathrm{d}]}$ \\
2 & & 25 & 5 & $95: 05$ & 81 & 89 \\
$3^{[\mathrm{e}]}$ & & -15 & 30 & $99: 01$ & 70 & 92 \\
$4^{[\mathrm{[}]}$ & & 25 & 30 & $97: 03$ & 73 & 81 \\
$5^{[\mathrm{g}]}$ & & 25 & 30 & $96: 04$ & 69 & 78 \\
6 & endo-L-4aa & 25 & 30 & $96: 04$ & 83 & -81 \\
7 & & -15 & 30 & $99: 01$ & 80 & -84 \\
8 & exo' $^{\prime}-\mathrm{L}-4 \mathbf{a a}$ & 25 & 30 & $42: 58$ & 75 & -24 \\
9 & endo-L-4ad $^{25}$ & 25 & 30 & $92: 08$ & 85 & -47
\end{tabular}

[a] Determined on crude reaction mixtures after $>99 \%$ conversion. [b] Determined by ${ }^{1} \mathrm{H}$ or ${ }^{19} \mathrm{~F}$ NMR on crude reaction mixtures [c] Isolated yields of anti and syn aldols after workup. [d] Determined by HPLC with chiral stationary phases and computed as ee $\left.=100 \times\left[2 D 1^{\prime} S\right)-\left(2 S, 1^{\prime} R\right)\right] /\left[\left(2 R, 1^{\prime} S\right)+\left(2 S, 1^{\prime} R\right)\right]$. [e] Results reported in 26 f] Acetic acid was used as additive. [g] 4-Nitrobenzoic acid was used as additive.

We also investigated the effect of including para-substituents on the 3,5-diphenyl groups of exo-L-4aa. To this end, the behavior of cycloadducts exo-L-4ea-dc was analyzed. The results are reported in Table 5. All these compounds provided satisfactory chemical yields and antilsyn diastereoselectivities. Interestingly enough, these effects do not seem to be additive, because neither two fluorine atoms (Table 5, Entry 5) nor one methoxy and one fluorine substituent (Table 5, Entry 6) produced $k_{\text {obs }}$ values higher than those obtained with the monosubstituted cycloadducts. Despite the modest acceleration observed with respect to exo-L-4aa, the measured enantiomeric excesses were found to be slightly lower than those found for the parent catalyst.

We next explored other substitution patterns in cycloadducts exo-L-4. In Table 6 we report the results obtained with respect to L-Pro. We observed that the free amino acid exo-L-4'aa, obtained by hydrolysis of methyl ester exo-L4aa (Scheme 3), retains the antilsyn diastereoselectivity and the sense of enantioselection, although with a slightly lower enantiomeric excess and chemical yield (Table 6, Entry 3). In the case of endo-L-4' aa (Table 6, Entry 3), the ee has the same sign as observed with the naturally occurring L-Pro 
Table 5. Pseudo-first ${ }^{[\mathrm{a}]}$ order kinetic constants $\left(k_{\text {obs }}\right)$, chemical yields, ${ }^{[b]}$ and enantiomeric excesses $(e e)^{[\mathrm{cc}]}$ observed in reaction 1a $+\mathbf{2 a} \rightarrow$ 3aa catalyzed by compounds exo-L-4ea-dc.
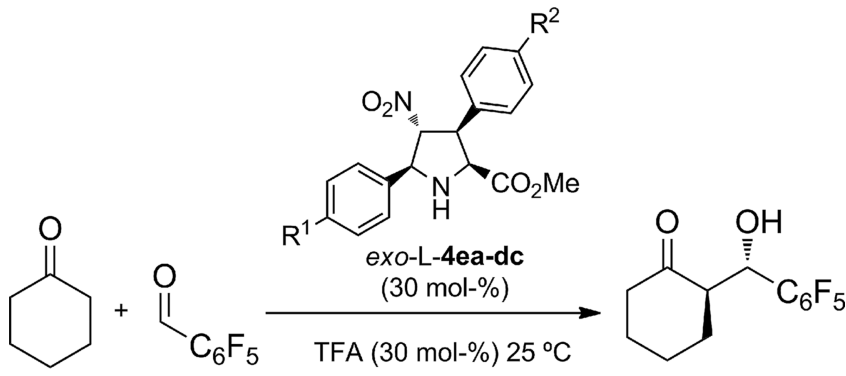

$1 a$

$2 a$

$(2 R, 1 ' S)-3 a a$

\begin{tabular}{llllccl}
\hline Entry & Cat. & $\mathrm{R}^{1}$ & $\mathrm{R}^{2}$ & Yield [\%] & $e e[\%]$ & $k_{\text {obs }}\left(\times 10^{-4} \mathrm{~s}^{-1}\right)$ \\
\hline 1 & exo-L-4ea & $\mathrm{F}$ & $\mathrm{H}$ & 80 & 78 & $6.23( \pm 0.19)$ \\
\hline 2 & exo-L-4ac & $\mathrm{H}$ & $\mathrm{F}$ & 72 & 83 & $10.18( \pm 0.36)$ \\
\hline 3 & exo-L-4da & OMe & $\mathrm{H}$ & 68 & 77 & $11.28( \pm 0.35)$ \\
4 & exo-L-4ab & $\mathrm{H}$ & $\mathrm{OMe}$ & 78 & 87 & $14.74( \pm 0.78)$ \\
5 & exo-L-4ec & $\mathrm{F}$ & $\mathrm{F}$ & 88 & 81 & $5.59( \pm 0.08)$ \\
6 & exo-L-4dc & OMe & $\mathrm{F}$ & 79 & 76 & $8.64( \pm 0.35)$
\end{tabular}

[a] All reactions were monitored at $25^{\circ} \mathrm{C}$ with a $\mathbf{1 a} / \mathbf{2 a}$ ratio of $60: 1$ until conversion $>99 \%$. In each case the antilsyn ratio was about 95:5. [b] Isolated yields of 3aa. [c] Enantiomeric excesses corresponding to the major anti diastereomer were determined by HPLC and computed as ee $=100 \times\left[\left(2 R, 1^{\prime} S\right)-\left(2 S, 1^{\prime} R\right)\right] /\left[\left(2 R, 1^{\prime} S\right)+\right.$ $\left.\left(2 S, 1^{\prime} R\right)\right]$

(Table 6, Entry 1). This change in the sense of chiral induction is discussed in more detail below. The presence of an alkoxy group bulkier than a methoxy group (compound exo-L-4ba, Table 6, Entry 4) also resulted in a lower ee and chemical yield. This detrimental effect was more pronounced in the case of a 2-naphthyl group at $C 5$ (compound exo-L-4ca, Table 6, Entry 5). Finally, we found that either a quaternary group at $C 2$ or a tert-butyl group at $C 5$ (compounds exo-L-4ha, exo-L-4ia, and exo-L-4fa) resulted in an almost complete loss of organocatalytic activity (Table 6, Entries 6-9). Therefore, the substitution patterns included in Entries 4-9 of Table 6 should be avoided in the development of other catalysts based on this scaffold.

We also tested the stereoselectivity and catalytic efficiency of selected compounds $\mathbf{4}$ in the absence of any acid additive. The results are reported in Table 7 and indicate that under these conditions the reaction times required for esters exo- and endo-L-4aa are much longer (Entries 1 and $2)$. In addition, the ee values are considerably lower, although the sense of induction was that obtained in the presence of TFA or other acids. In the case of acids exo-L-4' aa and endo-L-4' aa (Entries 3 and 4) the reaction times were considerably shorter than those observed with the corre391 sponding esters. In addition, the ee values were also lower than those achieved with the corresponding esters in the presence of TFA (Table 6, Entries 2 and 3). However, it is noteworthy that the sense of chiral induction of these compounds is the same as observed for the corresponding esters
Table 6. Stereocontrol and chemical yields observed ${ }^{[a]}$ in the 1a + $\mathbf{2 a} \rightarrow \mathbf{3 a a}$ reaction catalyzed by L-Pro and by substituted exo-L-4 cycloadducts $(30 \mathrm{~mol}-\%)$ in the presence of TFA (30 $\mathrm{mol}-\%)$.

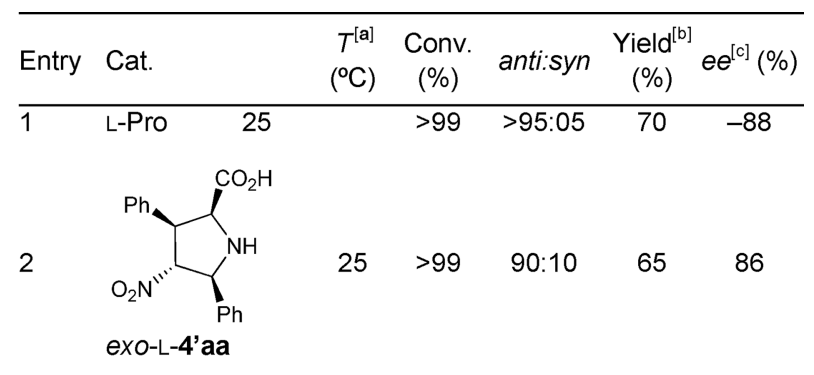

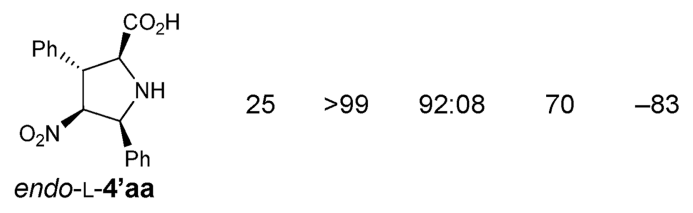

4

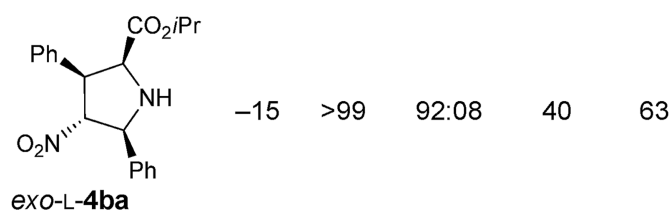

5

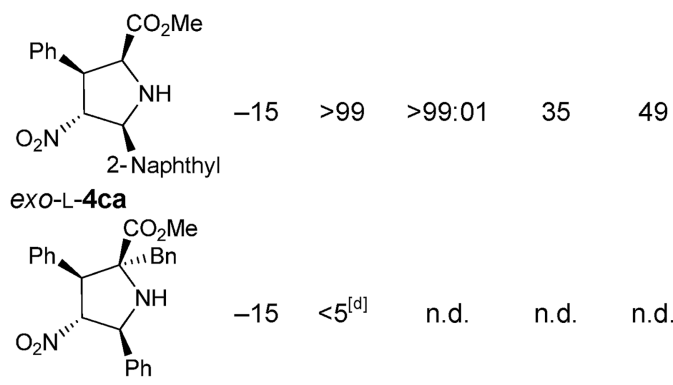

exo-L-4ha<smiles>CO[14C](=O)[C@@]1(c2ccccc2)N[C@H](c2ccccc2)[C@H]([N+](=O)[O-])[C@@H]1c1ccccc1</smiles>
$-15$ $<1^{\text {[d] }}$ n.d. n.d. n.d.

8 exo-L-4ia

8

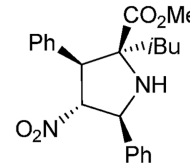
25 n.d. n.d. n.d. exo-L-4ia<smiles>CO[C@H]1N[C@H](C(C)(C)C)[C@@H]([N+](=O)[O-])[C@H]1c1ccccc1</smiles>
25 $35^{[\mathrm{d}]}$ 53:47 n.d. 12

[a] All reactions were monitored for $24 \mathrm{~h}$, with a $\mathbf{1 a} / \mathbf{2} \mathbf{a}$ ratio of $60: 1$. [b] Isolated yields of 3aa. [c] Enantiomeric excesses corresponding to the anti diastereomer were determined by HPLC on crude reaction mixtures and computed as ee $=100 \times\left[\left(2 R, 1^{\prime} S\right)-\left(2 S, 1^{\prime} R\right)\right]$ $\left[\left(2 R, 1^{\prime} S\right)+\left(2 S, 1^{\prime} R\right)\right]$. [d] Observed levels of conversion after $48 \mathrm{~h}$.

most convenient reaction conditions correspond to the unnatural proline esters 4 with TFA (30 mol- $\%$ ), in terms of 
stereocontrol, reaction rate, and preparative simplicity of the synthetic organocatalysts.

Table 7. Stereocontrol and chemical yields observed ${ }^{[a]}$ in the $\mathbf{1 a}+$ $\mathbf{2 a} \rightarrow \mathbf{3 a a}$ reaction catalyzed by substituted exo- and endo-L-4aa, exo-L-4' aa, and endo-L-4' aa cycloadducts without acidic additives.

Entry Cat. $t(\mathrm{~h})$ anti:syn $\begin{gathered}\mathrm{Yield}^{[\mathrm{b}]} \\ (\%)\end{gathered} \begin{gathered}\mathrm{ee}^{[\mathrm{c}]} \\ (\%)\end{gathered}$

[a] All reactions were monitored at $25^{\circ} \mathrm{C}$ with a 1a/2a ratio of $60: 1$ until $99 \%$ conversion. [b] Isolated yields of 3aa. [c] Enantiomeric excesses corresponding to the anti diastereomer were determined by HPLC on crude reaction mixtures and computed as ee = $100 \times\left[\left(2 R, 1^{\prime} S\right)-\left(2 S, 1^{\prime} R\right)\right] /\left[\left(2 R, 1^{\prime} S\right)+\left(2 S, 1^{\prime} R\right)\right]$.

\section{Stereoselectivity of Organocatalysts exo-L-4aa and endo-L-} 4aa

In Table 4 we reported that exo-L-4aa yields the aldol adduct $\left(2 R, 1^{\prime} S\right)$-3aa as the major stereoisomer of the $\mathbf{1 a}+$ $\mathbf{2 a} \rightarrow \mathbf{3 a a}$ reaction, with $92 \%$ ee at $-15^{\circ} \mathrm{C}$. In contrast, endoL-4aa yields $\left(2 S, 1^{\prime} R\right)$-3aa as the major adduct, with $84 \%$ ee under the same reaction conditions. The latter adduct is the enantiomer obtained in the presence of natural L-Pro (Table 6, Entry 1). In order to explore the persistence of this enantiodivergent behavior for exo-L-4aa and endo-L-4aa, we studied different aldol reactions involving ketones $\mathbf{1 a}-\mathbf{c}$ and aldehydes $\mathbf{2 a}-\mathbf{f}$ (Scheme 6). The results obtained are collected in Table 7.

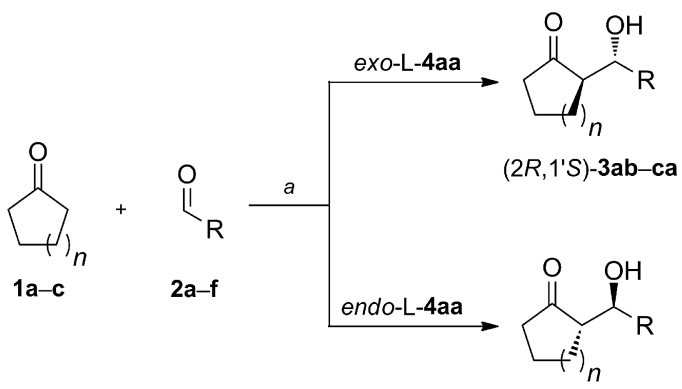

$$
\begin{array}{ll}
\text { 1a: } n=2 & \text { 2a: } \mathrm{R}=\mathrm{C}_{6} \mathrm{~F}_{5} \\
\text { 1b: } n=1 & \text { 2b: } \mathrm{R}=4-\mathrm{NO}_{2} \mathrm{C}_{6} \mathrm{H}_{4} \\
\text { 1c: } n=3 & \text { 2c: } \mathrm{R}=4-\mathrm{CF}_{3} \mathrm{C}_{6} \mathrm{H}_{4} \\
& \text { 2d: } \mathrm{R}=3-\mathrm{CH}_{3} \mathrm{C}_{6} \mathrm{H}_{4} \\
& \text { 2e: } \mathrm{R}=3-\mathrm{NO}_{2} \mathrm{C}_{6} \mathrm{H}_{4} \\
& \text { 2f: } \mathrm{R}=3,5-\mathrm{F}_{2} \mathrm{C}_{6} \mathrm{H}_{3}
\end{array}
$$

Scheme 6. Aldol reactions between ketones 1a-c and aldehydes 2af catalyzed by endo-L-4aa and exo-L-4aa. Reagents and conditions: (a) organocatalyst $(30 \mathrm{~mol}-\%)$, TFA $(30 \mathrm{~mol}-\%),-15$ or $+25^{\circ} \mathrm{C}$, 24 h (see Table 7).

Consistent behavior was observed for reactions between cyclohexanone (1a) and aldehydes 2a-f (Tables 4 and 8). Thus, in the presence of organocatalyst exo-L-4aa, aldol adducts $\left(2 R, 1^{\prime} S\right)-\mathbf{3 a a}-\mathbf{a f}$ were obtained with ee values of

\begin{tabular}{|c|c|c|c|c|c|c|c|}
\hline Entry & $n$ & $\mathrm{R}$ & Cat. & Aldol & anti/syn $n^{[\mathrm{c}]}$ & Yield $[\%]$ & $e e^{[\mathrm{d}]}[\%]$ \\
\hline $1^{[\mathrm{a}]}$ & 2 & $4-\mathrm{NO}_{2} \mathrm{C}_{6} \mathrm{H}_{4}$ & exo-L-4aa & $\left(2 R, 1^{\prime} S\right)-\mathbf{3 a b}$ & $85: 15$ & $81^{[\mathrm{e}]}$ & 92 \\
\hline $2^{[\mathrm{a}]}$ & 2 & $4-\mathrm{NO}_{2} \mathrm{C}_{6} \mathrm{H}_{4}$ & endo-L-4aa & $\left(2 S, 1^{\prime} R\right)-\mathbf{3 a b}$ & $88: 12$ & $84^{[\mathrm{e}]}$ & -90 \\
\hline $3^{[\mathrm{a}]}$ & 2 & $4-\mathrm{CF}_{3} \mathrm{C}_{6} \mathrm{H}_{4}$ & exo-L-4aa & $\left(2 R, 1^{\prime} S\right)-\mathbf{3 a c}$ & $86: 14$ & $79^{[\mathrm{e}]}$ & 94 \\
\hline $4^{[\mathrm{a}]}$ & 2 & $4-\mathrm{CF}_{3} \mathrm{C}_{6} \mathrm{H}_{4}$ & endo-L-4aa & $\left(2 S, 1^{\prime} R\right)-\mathbf{3 a c}$ & $85: 15$ & $83^{[\mathrm{e}]}$ & -70 \\
\hline $5^{[\mathrm{a}]}$ & 2 & $3-\mathrm{MeC}_{6} \mathrm{H}_{4}$ & exo-L-4aa & $\left(2 R, 1^{\prime} S\right)-\mathbf{3 a d}$ & $85: 15$ & $70^{[\mathrm{e}]}$ & 92 \\
\hline $6^{[\mathrm{a}]}$ & 2 & $3-\mathrm{MeC}_{6} \mathrm{H}_{4}$ & endo-L-4aa & $\left(2 S, 1^{\prime} R\right)-3 \mathbf{a d}$ & $83: 17$ & $75^{[\mathrm{e}]}$ & -66 \\
\hline $7^{[\mathrm{a}]}$ & 2 & $3-\mathrm{NO}_{2} \mathrm{C}_{6} \mathrm{H}_{4}$ & exo-L-4aa & $\left(2 R, 1^{\prime} S\right)-\mathbf{3 a e}$ & $80: 20$ & $60^{[\mathrm{e}]}$ & 94 \\
\hline $8^{[\mathrm{a}]}$ & 2 & $3-\mathrm{NO}_{2} \mathrm{C}_{6} \mathrm{H}_{4}$ & endo-L-4aa & $\left(2 S, 1^{\prime} R\right)-\mathbf{3 a e}$ & $80: 20$ & $65^{[\mathrm{e}]}$ & -64 \\
\hline $9^{[\mathrm{a}]}$ & 2 & $3,5-\mathrm{F}_{2} \mathrm{C}_{6} \mathrm{H}_{3}$ & exo-L-4aa & $\left(2 R, 1^{\prime} S\right)-\mathbf{3 a f}$ & $85: 15$ & $55^{[\mathrm{e}]}$ & 86 \\
\hline $10^{[\mathrm{a}]}$ & 2 & $3,5-\mathrm{F}_{2} \mathrm{C}_{6} \mathrm{H}_{3}$ & endo-L-4aa & $\left(2 S, 1^{\prime} R\right)-\mathbf{3 a f}$ & $83: 17$ & $67^{[\mathrm{e}]}$ & -74 \\
\hline $11^{[\mathrm{b}]}$ & 1 & $\mathrm{C}_{6} \mathrm{~F}_{5}$ & exo-L-4aa & $\left(2 R, 1^{\prime} S\right)-\mathbf{3 b a}$ & $82: 18$ & $65^{[\mathrm{e}]}$ & 15 \\
\hline $12^{[\mathrm{b}]}$ & 1 & $\mathrm{C}_{6} \mathrm{~F}_{5}$ & endo-L-4aa & $\left(2 S, 1^{\prime} R\right)-\mathbf{3 b a}$ & $89: 11$ & $45^{[\mathrm{e}]}$ & -10 \\
\hline $13^{[\mathrm{b}]}$ & 3 & $\mathrm{C}_{6} \mathrm{~F}_{5}$ & exo-L-4aa & $\left(2 R, 1^{\prime} S\right)-\mathbf{3 c a}$ & 99:01 & $40^{[\mathrm{f}]}$ & 59 \\
\hline $14^{[\mathrm{b}]}$ & 3 & $\mathrm{C}_{6} \mathrm{~F}_{5}$ & endo-L-4aa & $\left(2 S, 1^{\prime} R\right)-\mathbf{3 c a}$ & 99:01 & $84^{[\mathrm{f}]}$ & -35 \\
\hline
\end{tabular}
about $90 \%$. In comparison, use of endo-L-4aa provided the enantiomeric adducts $\left(2 S, 1^{\prime} R\right)-\mathbf{3 a a}-\mathbf{a f}$ as major isomers, with slightly lower enantiomeric excesses. Cyclopentanone

Table 8. Stereocontrol and chemical yields observed ${ }^{[a, b]}$ in the $\mathbf{1 a}-\mathbf{c}+\mathbf{2 a}-\mathbf{f} \rightarrow \mathbf{3 a b}-\mathbf{c a}$ reactions (Scheme 6) catalyzed by cycloadducts exoL-4aa and endo-L-4aa.

[a] Reactions carried out at $-15^{\circ} \mathrm{C}$. [b] Reactions carried out at $25^{\circ} \mathrm{C}$. [c] Ratios determined by ${ }^{1} \mathrm{H}$ NMR examination of the crude reaction mixtures. [d] Enantiomeric excesses corresponding to the major anti aldol adducts determined by HPLC with a chiral stationary phase and computed as $e e=100 \times\left[\left(2 R, 1^{\prime} S\right)-\left(2 S, 1^{\prime} R\right)\right] /\left[\left(2 R, 1^{\prime} S\right)+\left(2 S, 1^{\prime} R\right)\right]$. [e] Yields of isolated aldol adducts after conversion $>99 \%$. [f] Yields of isolated aldol adducts after $48 \mathrm{~h}$ with conversion of $96 \%$. 
421 (1b) was more reactive than 1a, but the enantiocontrol was found to be much lower (Table 8, Entries 11 and 12). The stereoselectivity observed with cycloheptanone (1c) was also lower than that found with 1a, although the enantiocontrol was somewhat higher than that obtained for $\mathbf{1 b}$ (Table 8, Entries 13 and 14). Therefore, cyclohexanone appears to represent a good compromise between reactivity and enantiocontrol in these reactions.

From these results it is clear that the stereochemical behavior of exo-L-4aa-ec (see also Table 5 and Table 6) is ex-

431 ceptional and completely different from that observed for L-Pro itself and other organocatalysts such as endo-L-4aa, exo'-L-4aa, and endo-L-4ad. In order to understand the reasons for this unexpected outcome, we decided to undertake a computational study of the model aldol reaction 1a

$436+\mathbf{2 a} \rightarrow \mathbf{3 a a}$ in the presence of exo-L-4aa and endo-L-4aa. According to the accepted model for this reaction, the stereochemically relevant step is $\mathrm{C}-\mathrm{C}$ bond formation from the enamine intermediates of type INT1 and aldehydes 2 . In the case of the $\mathbf{1 a}+\mathbf{2} \mathbf{a} \rightarrow \mathbf{3} \mathbf{a} \mathbf{a}$ reaction, the enamine inter441 mediate can exist in two families of conformers INT1a and INT1'a depending on the $s$-cis or s-trans disposition, respectively, between the double bond of the enamine moiety and the methoxycarbonyl group (Scheme 7).

If we define the dihedral angle $\omega$ as $\omega=\mathrm{C} a-\mathrm{N} b-\mathrm{C} c-\mathrm{C} d$ (Figure 6), $s$-cis conformations will be obtained for $\omega$ values between 0 and \pm 75 deg., whereas $s$-trans conformations can be grouped for $\omega \&$ epsis; $( \pm 95, \pm 180)$. MM3 molecular dynamics (MD) simulations (Figure 6) show different behavior of intermediates exo-INT1a and endo-INT1a, although 451 in both cases both conformations are significantly populated. Both MD and Monte Carlo simulations show a remarkable conformational rigidity in the pyrrolidine ring, with three substituents occupying equatorial positions and one being isoclinal. In contrast, the cyclohexenyl moiety is 456 much more flexible. At the M06-2X(PCM)/6-31+G**// B3LYP(PCM)/6-31G*+ 2 ZPVE level, exo-INT1a was calculated to be $0.4 \mathrm{kcalmol}^{-1}$ less stable than the exo-INT1'a conformer, whereas the reverse relative stability was found for the endo analogues (see Figure S5 in the Supporting In461 formation). Therefore, from these analyses, no general kinetic stereoselectivity trends can be envisaged for the aldol reaction in the presence of organocatalysts exo-L-4aa and endo-L-4aa.

If we consider the interaction pathways of the intermediate exo-INT1a, derived from exo-L-4aa with aldehyde $\mathbf{2 a}$, in principle these interactions can occur through both the nitro and methoxycarbonyl $(\mathrm{X}=\mathrm{Me})$ or carboxy $(\mathrm{X}=\mathrm{H})$ groups, as depicted in Scheme 7. In addition, depending upon the reaction conditions, the elementary step leading

471 to the formation of the $\mathrm{C}-\mathrm{C}$ bond can involve different $\mathrm{Y}$ species. Thus, under non-acidic conditions $\mathrm{Y}$ can be $\mathrm{H}_{2} \mathrm{O}$ (formed as a consequence of the generation of exo-INT1a in situ) or nothing. Similarly, reaction conditions including acidic additives can give rise to structures in which $\mathrm{Y}=\mathrm{H}^{+}$ or $\mathrm{H}_{3} \mathrm{O}^{+}$(Scheme 7). The possible combinations generate a very complex situation in which many alternative transition structures can be present. However, intensive searching of

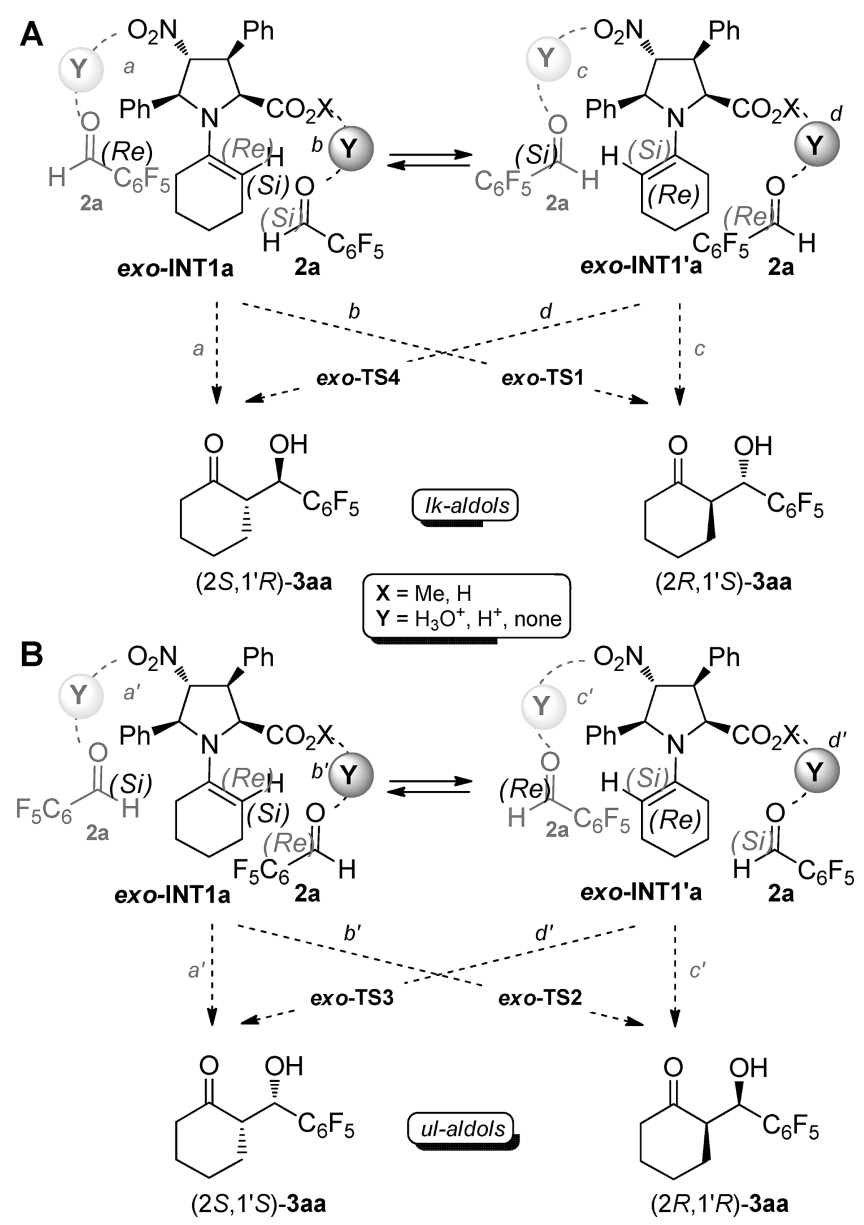

Scheme 7. (A) "Like" reaction path, and (B) "unlike" reaction path associated with the $\mathrm{C}-\mathrm{C}$ bond-forming step of the aldol reaction between cyclohexanone and pentafluorobenzaldehyde (2a) in the presence of organocatalyst exo-L-4aa.

these saddle points along different topologies at the $\mathrm{B} 3 \mathrm{LYP}(\mathrm{PCM}=$ cyclohexanone $) / 6-31 \mathrm{G}^{*}$ level of theory met with no success in the case of the interaction of $\mathbf{2 a}$ with exo-INT1a through the nitro group (paths $a, a^{\prime}, b$, and $b^{\prime}$, Scheme 7) when $\mathrm{X}=\mathrm{OMe}$ and $\mathrm{Y}=$ nothing, $\mathrm{H}^{+}$. For $\mathrm{Y}=$ $\mathrm{H}_{3} \mathrm{O}^{+}$, saddle points associated with interaction patterns $a$ and $c$ through the nitro group were located, but were found to lie ca. $4 \mathrm{kcal} \mathrm{mol}^{-1}$ above their analogues exo-TS1 and exo-TS4 (see Figure S6 in the Supporting Information), in which the interaction between exo-INT1a and 2a takes place through the methoxycarbonyl group (Scheme 7, interaction modes $b$ and $d$ ). Therefore, we will restrict the following discussion to transition structures involving $\mathrm{X}=\mathrm{H}, \mathrm{Me}$ and $\mathrm{Y}=\mathrm{H}^{+}$through the interaction patterns $b, b^{\prime}, d$, and $d^{\prime}$ shown in Scheme 7.

The chief geometric features and relative energies of saddle points exo-TS1-4 [M06-2X(PCM = cyclohexanone $) / 6-31+\mathrm{G}^{* *} / / \mathrm{B} 3 \mathrm{LYP}(\mathrm{PCM}=$ cyclohexanone $) / 6-31 \mathrm{G}^{*}$ level of theory] are shown in Figure 7. These transition structures show Houk-List geometries ${ }^{[23]}$ in which three substituents of the pyrrolidine ring occupy equatorial positions in half-chair conformations and the methoxycarbonyl group, in general constrained by the hydrogen bond with 

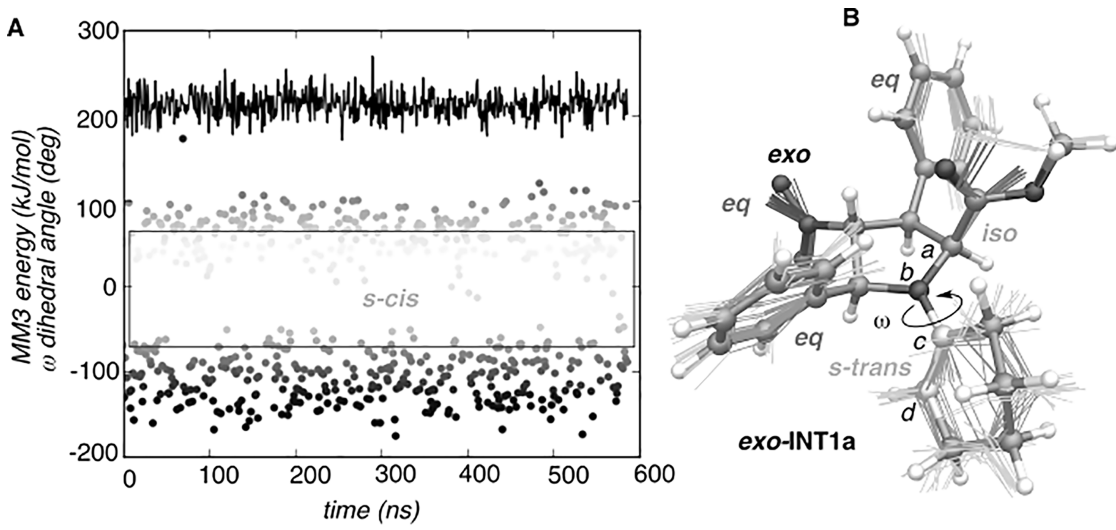

\section{B}
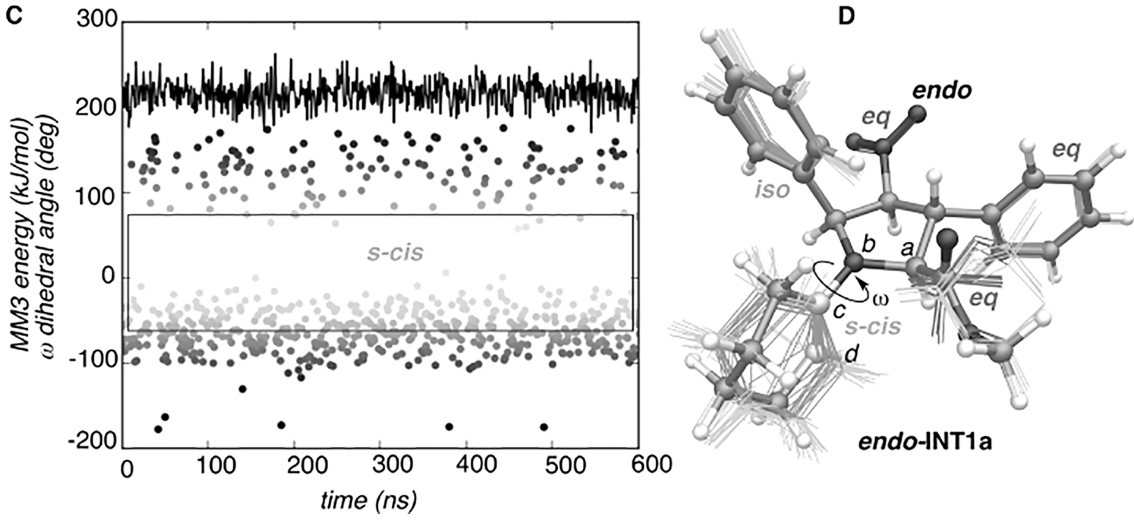

Figure 6. Molecular dynamics plots for (A) exo-INT1a, and (C) endo-INT1a, computed with use of the MM3 forcefield. The Ca-N $b-C c$ $\mathrm{C} d$ dihedral angle is denoted $\omega$. Areas denoted $s$-cis include structures for which $\omega \leq \pm 75 \mathrm{deg}$. Monte Carlo conformational analyses calculated with MM3 for (B) exo-INT1a, and (D) endo-INT1a. Ball and stick representations correspond to the lowest-energy conformers, and the wire structures include the 20 most stable conformers within 2.6 and $2.9 \mathrm{kcal} \mathrm{mol}^{-1}$, respectively.

the protonated aldehyde, occupies an isoclinal position (Figure 7). The Bürgi-Dunitz angles defined by $C c, \mathrm{C} b$, and the $\mathrm{OH}$ group vary from 100.5 to $106.9^{\circ}$. The dihedral angle $\phi$ defined as $\phi=\mathrm{C} a-\mathrm{Cb}-\mathrm{Cc}-\mathrm{C} d$ (Figure 8) shows values close to $+100^{\circ}$ in exo-TS2 and $-100^{\circ}$ in exo-TS3. This dihedral angle is closer to $180^{\circ}$ in exo-TS1 and exo-TS4. The former saddle point, which is the transition structure of lowest energy, shows an s-cis conformation of the enamine moiety and an antiperiplanar conformation of this group with respect to the $\mathrm{C}_{6} \mathrm{~F}_{5}$ substituent, with $\phi=-174.1^{\circ}$, thus minimizing the steric repulsion generated by the 5-phenyl group of exo-L-4aa. These features make exo-TS1 the least energetic transition structure associated with the $\mathrm{C}-\mathrm{C}$ bond-forming step of the 1a $+\mathbf{2 a} \rightarrow \mathbf{3 a a}$ reaction in the presence of organocatalyst exo-L-4aa. This transition structure leads to antialdol $\left(2 R, 1^{\prime} S\right)-3$ aa, in good agreement with the experimental results. The calculated antilsyn ratio is $>99: 01$, and the computed ee for the anti isomers in the presence of exo-L4aa is $>99 \%$. Both results are in qualitative agreement with the experimentally determined values of $95: 05$ and $89 \%$, respectively (Table 4, Entries 1 and 2).

It is worth noting that when $\mathrm{X}=\mathrm{H}$ and $\mathrm{Y}=$ none, the corresponding Houk-List saddle point exo-TS1 is $0.8 \mathrm{kcal} \mathrm{mol}^{-1}$ lower in energy than its exo-TS4 analogue (see Figure S7 in the Supporting Information), a result pleasingly in agreement with the experimentally observed lower ee for exo-L-4' aa in the absence of TFA (Table 7, Entry 4).

The transition structures endo-TS1-4 associated with the $\mathbf{1 a}+\mathbf{2 a} \rightarrow \mathbf{3 a a}$ reaction catalyzed by endo-L-4aa (Figure 8) show non-optimal geometric features in all cases. Thus, endo-TS1-3 each show one axial and two isoclinal groups in the pyrrolidine ring, and only endo-TS4 is able to accommodate four equatorial substituents, but at the cost of a certain steric congestion between the $\mathrm{C}_{6} \mathrm{~F}_{5}$ group and the equatorial phenyl group at $C 5$ of the organocatalyst (Figure 8). This tradeoff between unfavorable features might be responsible for the slightly lower catalytic activity observed for endo-L-4aa (Figure 4 and Table 1, Entry 3). The reverse enantioselectivity observed for this catalyst with respect to exo-L-4aa is also compatible with the relative energies shown in Figure 8. Saddle point endo-TS4 has suitable Bürgi-Dunitz and $\phi$ angles, the four substituents of the pyrrolidine ring being in equatorial positions. In addition, this transition structure can develop a strong hydrogen bond between the $\mathrm{OH}$ group being formed and the methoxycarbonyl group. However, the s-trans conformation of the cyclohexenyl moiety imposes a close proximity between the $\mathrm{C}_{6} \mathrm{~F}_{5}$ group of the electrophile and the 5-phenyl group of endo-L-4aa. This unfavorable steric congestion does not overcome the other favorable features of endo-TS4, thus making this stationary point, which leads to anti aldol 

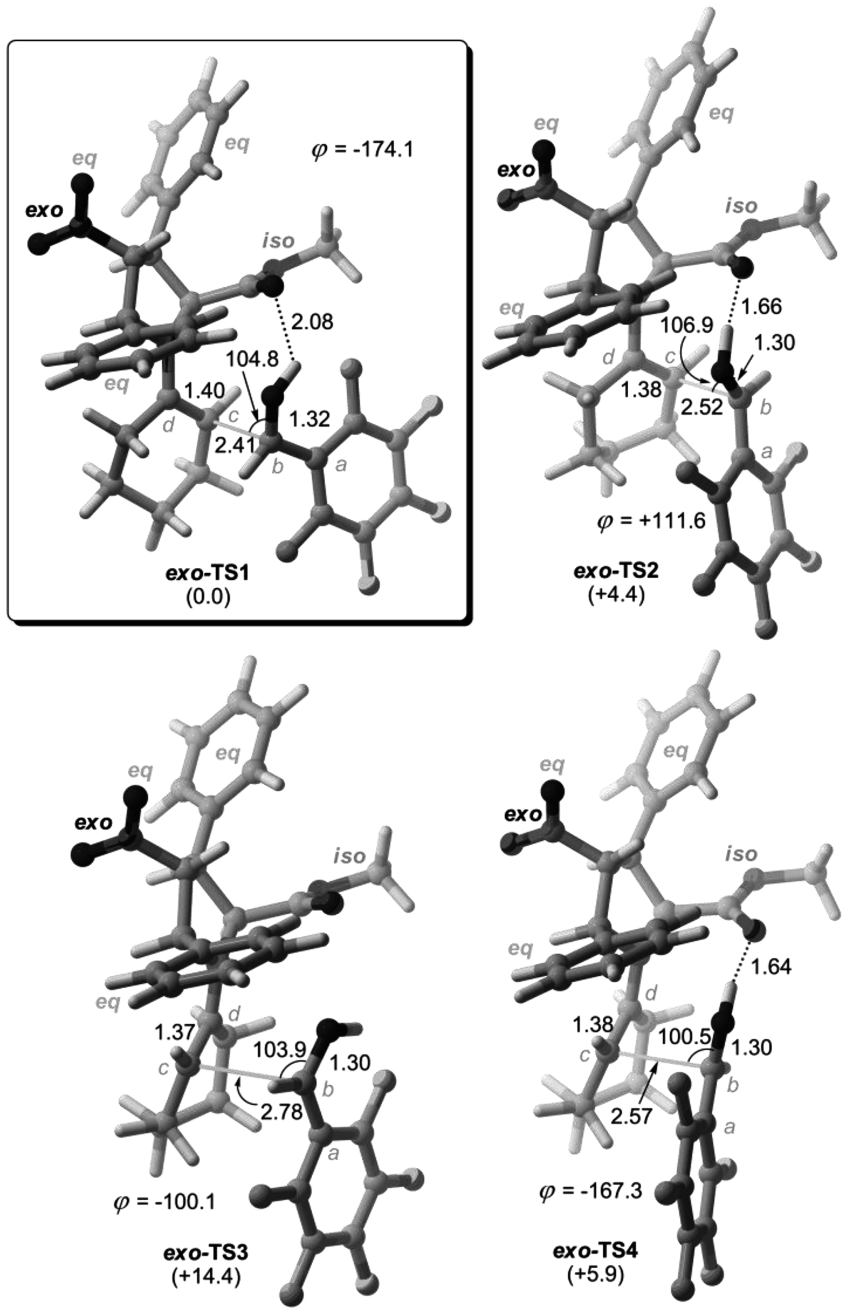

Figure 7. Chief features of transition structures exo-TS1-4 fully optimized at the B3LYP(PCM)/6-31G* level of theory. Bond lengths and angles are given in $\AA$ and deg., respectively. The dihedral angle defined by $\mathrm{C} a, \mathrm{Cb}, C c$, and $\mathrm{C} d$ atoms is denoted $\phi$. Numbers in parentheses correspond to relative energies (in $\mathrm{kcalmol}^{-1}$ ) computed at the M06-2X(PCM)/6-31+G**//B3LYP(PCM)/6$31 \mathrm{G}^{*}+\Delta \mathrm{ZPVE}$ level. Equatorial and isoclinal positions are denoted $e q$ and iso, respectively.

$\left(2 S, 1^{\prime} R\right)-3 \mathbf{a a}$, the lowest-energy saddle point of this series. The calculated antilsyn ratio at $298 \mathrm{~K}$ is $97: 03$ and the ee for the anti aldols is $>99 \%$. Once again, these results are in qualitative agreement with the experimental data at $298 \mathrm{~K}$ [96:04 and 81\% (absolute value), respectively (Table 4, Entry 4)].

These combined experimental and computational data

561 indicate that densely substituted proline-based organocatalysts can show unexpected organocatalytic properties. Thus, aside from the geometric and stereoelectronic effects imposed by the Houk-List geometries, subtle remote effects stemming from conformational preferences in the pyrrolidinone ring can result in unique asymmetric induction effects, not available for organocatalysts based on natural Lamino acids such as L-Pro.
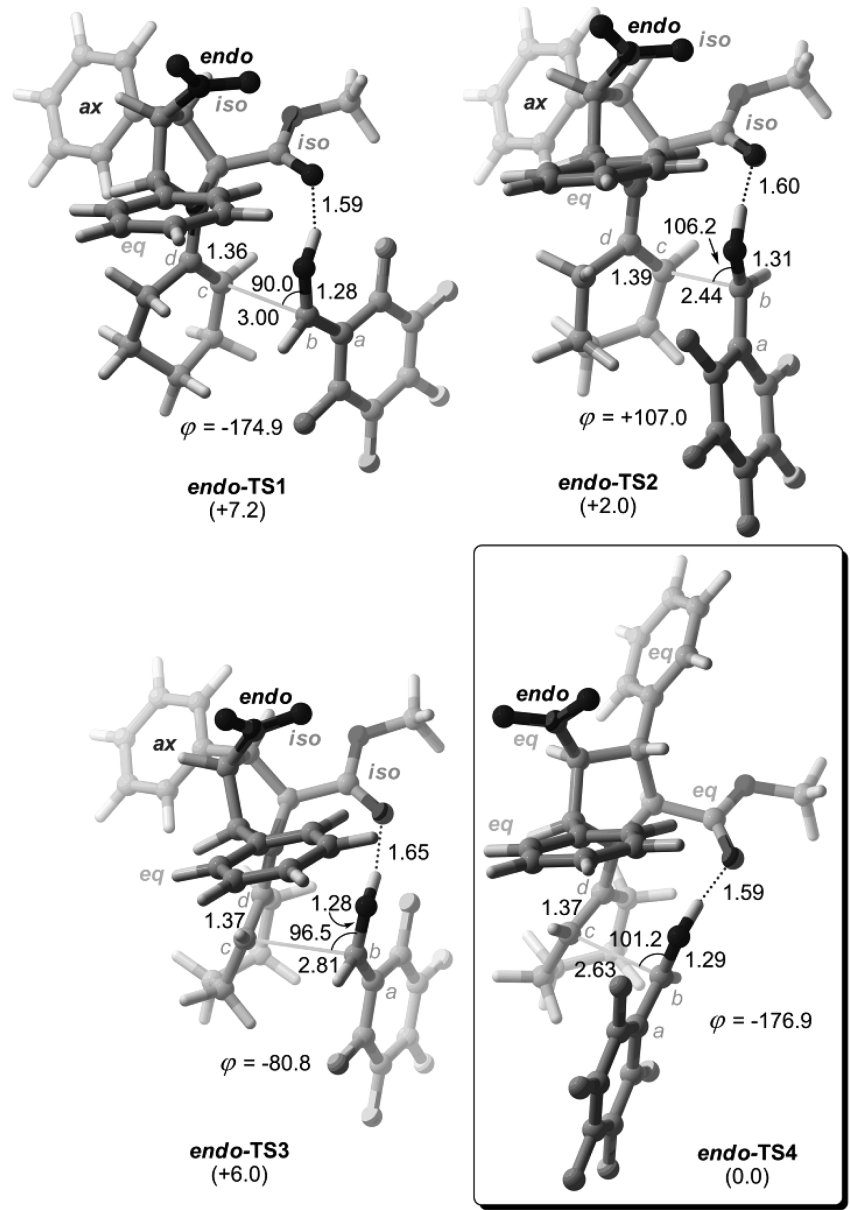

Figure 8. Chief features of transition structures endo-TS1-4 fully optimized at the B3LYP(PCM)/6-31G* level of theory. See the caption of Figure $7 \square((<=$ Author: change correct? was 8$)) \boldsymbol{\square}$ for further details.

\section{Conclusions}

From the experimental and computational data reported in this study the following conclusions can be drawn: (i) densely substituted unnatural proline esters, readily accessible through asymmetric [3+2] cycloadditions, can be used as efficient organocatalysts for aldol reactions, and methyl esters in the presence of TFA are superior to the corresponding acids in terms of accessibility, reaction rate, and stereocontrol, (ii) in these systems, substituents at positions $C 3$ and $C 4$ of the pyrrolidine ring must be trans to each other, (iii) quaternary centers at $C 2$ destroy the catalytic activity, (iv) aryl groups at $C 5$ are preferable to alkyl groups, (v) bulky alkoxycarbonyl groups at $C 2$ must be avoided, (vi) the sense of induction of the organocatalysts depends on several factors (maximum number of equatorial substituents in the pyrrolidine ring, intramolecular hydrogen bonds, gauche disposition between the $\mathrm{N}-\mathrm{C}=\mathrm{C}$ and $\mathrm{C}=\mathrm{O}$ bonds in the transition structure, and potential steric clash between the substituent at $C 5$ and the substituent of the aldehyde), and (vii) according to the balance of these factors exo-L-proline esters preferentially yield anti 
$\left(2 R, 1^{\prime} S\right)$ aldols, whereas the endo organocatalysts yield the corresponding $\left(2 S, 1^{\prime} R\right)$ aldols as major products.

\section{Experimental Section}

Determination of Pseudo-First Order Kinetic Constants: 2,3,4,5,6Pentafluorobenzaldehyde (2a) $(0.1 \mathrm{mmol}, 20 \mathrm{mg}, 1$ equiv. $)$ and the corresponding organocatalyst $4(0.03 \mathrm{mmol}, 0.3$ equiv. $)$ were dissolved in neat, freshly distilled (MS, $3 \AA$ ) cyclohexanone (1a, $0.63 \mathrm{~mL}, 6 \mathrm{mmol}, 60$ equiv.) at room temperature. This mixture was transferred to a NMR tube, and then trifluoroacetic acid ( $0.03 \mathrm{mmol}, 2.3 \mu \mathrm{L}, 0.3$ equiv. in standard experiments) was added. The resulting mixtures were immediately introduced into the NMR 601 probe. Samples were stabilized at 298 K. The kinetic studies were performed by monitoring the three ${ }^{19} \mathrm{~F}$ NMR signals of free 2a, together with the other signals also associated with the $\mathrm{C}_{6} \mathrm{~F}_{5}$ group, obtained with inverse gate ${ }^{1} \mathrm{H}$-decoupling. Trifluoroacetic acid $(\delta=$ $-76 \mathrm{ppm}$ ) was used as internal reference. NMR measurements were 606 carried out at $376.40 \mathrm{MHz}$ with a Bruker Advance 400 NMR spectrometer, equipped with a $\mathrm{BBOF}$ probe incorporating $z$-gradients. FID files were obtained with a spectral window of $240 \mathrm{ppm}$ and transformed with 65536 points. All spectra were recorded by accumulating 16 acquisitions, with recycling delays of $1 \mathrm{~s}$. Measurements were performed directly on the reaction mixtures in the NMR tubes every $5 \mathrm{~min}$. Relative concentrations of $\mathbf{2 a}$ at different times were quantified by integration and statistical treatment of the three sets of ${ }^{19} \mathrm{~F}$ signals. Kinetic constants reported in Tables 1, 2, 3 , and 5 were obtained from the NMR experiments and application 616 of Equation (2). All KIE experiments reported in Table 3 were carried out in triplicate and subjected to further statistical treatment.

Molecular Dynamics: The MD simulations of intermediates INT1a and INT1'a were carried out with use of the MM3 forcefield ${ }^{[35]}$ as implemented in the MacroModel package. ${ }^{[36]}$ Calculations were

621 performed with $\mathrm{SHAKE}^{[37]}$ to constrain the $\mathrm{C}-\mathrm{H}$ bonds. The temperature was set up to $298 \mathrm{~K}$. The system was equilibrated for $1 \mathrm{~ns}$ with time steps of $1 \mathrm{fs}$. The production run was started from this point and lasted another 600 nanoseconds with time steps of $1 \mathrm{fs}$. In all cases we observed that during the production period the ening the production run, the coordinates of 500 structures were saved

DFT Calculations: Density functional theory calculations were performed by use of the Gaussian 09 suite of programs. ${ }^{[38]}$ Full geomeof the B3LYP hybrid functional ${ }^{[39]}$ and the $6-31 G^{*}$ basis set. Solvent effects were computed by the PCM method ${ }^{[40]}$ and with cyclohexanone as model solvent. Single-point energies were computed by use of the M06-2X functiona ${ }^{[41]}$ and the $6-31+\mathrm{G}^{* *}$ basis set. Free energies were computed at $298.15 \mathrm{~K}$.

\section{Acknowledgments}

Financial support was provided by the Spanish Ministerio de Economía y Competitividad (MINECO) and the Fondos Europeos para el Desarrollo Regional (FEDER) (projects CTQ2010-16959/BQU, CTQ2012-35535, CTQ2007-62771/BQU, CTQ2010-20387, CTQ2010-17436, and Consolider-Ingenio CSD2007-00006), the University of the Basque Country (UPV/EHU, UFI11/22 QOSYC), the Basque Government (GV/EJ, grant IT-324-07), the Generalitat Valenciana-FEDER (PROMETEO/2009/039), the Go-
Alicante. M. d. G. R. thanks the \#\#\#\#\#\#\# (DIPC) $\square((<=\mathrm{Au}-$ thor: please add the sponsor name, written in full length)) $\square$ for a postdoctoral contract. M. S. and L. C. gratefully thank MINECO for a contract funding their $\mathrm{PhD}$ projects. The authors thank the SGI/IZO-SGIker UPV/EHU and the DIPC for generous allocation of computational and analytical resources. Technical and human support provided by SGIker (UPV/EHU, MINECO, GV/EJ, ESF) is gratefully acknowledged.

[1] a) R. Mahrwald (Ed.), Modern Methods in Stereoselective Aldol Reactions, Wiley-VCH, Weinheim, Germany, 2011; b) R. Mahrwald (Ed.), Modern Aldol Reactions, Wiley-VCH, New York, vol. 1 and 2.

[2] a) W.-D. Fessner, A. Schneider, H. Held, G. Sinerius, C. Walter, M. Hixon, J. V. Schloss, Angew. Chem. Ed. Engl. 1996, 35, 2219-2221; Angew. Chem. 1996, 108, 23 5. L. J. Whalen, C. H. Wong, Aldrichim. Acta 2006, 39, 63-T1; c) T. D. Machajewski, C.-H. Wong, Angew. Ch nt. Ed. 2000, 39, 1352-1375; Angew. Chem. 2000, 112, 14 (5.) D. J. Kuo, I. A. Rose, Biochemistry 1985, 24, 3947-3955; e) A. Heine, L. J. G. Luz, C.-H. Wong, I. A. Wilson, J. Mol. Biol. 2004, 343, 1019-1030.

[3] U. Eder, G. Sauer, R. Wiechert, Angew. Cher Int. Ed. Engl. 1971, 10, 496-497; Angew. Chem. 1971, 83, 49@

[4] a) Z. G. Hajos, D. R. Parrish, German Patent De2120623; b) Z. G. Hajos, D. R. Parrish, J. Org. Chem. 1974, 39, 1615-1621.

5] a) B. List, R. A. Lerner, C. F. Barbas III, J. Am. Chem. Soc 2000, 122, 2395-2396; b) For the extension to an L-Pro-catalyzed Robinson reaction, see: T. Bui, C. F. Barbas III, Tetrahedron Lett. 2000, 41, 6951-6954; c) See also: C. F. Barbas III, Angey Cem. Int. Ed. 2008, 47, 42-47; Angew. Chem. 2008, 120,45

[6] B. List, P. Pojarliev, C. Castello, Org. Lett. 2001, 3, 573-575.

[7] a) W. Notz, F. Tanaka, C. F. Barbas III, Acc. Chem. Res. 2004, 37, 580-591; b) B. List, J. W. Yang, Science 2006, 313, 1584 1586; c) S. Mukherjee, J. W. Yang, S. Hoffmann, B. List, Chem. Rev. 2007, 107, 5471-5569; d) G. Guillena, C. Nájera, D. J. Ramón, Tetrahedron: Asymmetry 2007, 18, 2249-2293; e) M. J. Gaunt, C. C. C. Johansson, A. McNally, N. T. Vo, Drug Discovery Today 2007, 12, 8-27; f) A. Dondoni, A. Massi, Angew. Che t. Ed. 2008, 47, 4638-4660; Angew. Chem. 2008, 120, 471 P. Melchiorre, M. Marigo, A. Carlone, G. Bartoli, Angew. Ch nt. Ed. 2008, 47, 6138-6171; Angew. Chem. 2008, 120, 62 S. Bertelsen, K. A. Jørgensen, Chem. Soc. Rev. 2009, 38, 2178-2189; i) M. Nielsen, D. Worgull, T. Zweifel, B. Gschwend, S. Bertelsen, K. A. Jørgensen, Chem. Commun. 2010, 46, 632-649; j) J. G. Hernández, E. Juaristi, Chem. Commun. 2012, 48, 5396-5409.

[8] a) K. A. Ahrendt, C. J. Borths, D. W. C. MacMillan, J. Am Chem. Soc. 2000, 122, 4243-4244; b) D. W. C. MacMillan, Nature 2008, 455, 304-308.

[9] a) S. G. Zlotin, A. S. Kucherenko, I. P. Beletskaya, Russ. Chem. Rev. 2009, 78, 737-784; b) H. Wennemers, Chimia 2010, 64 864-865; c) U. Scheffer, R. Mahrwald, Synlett 2011, 1660 1667; d) V. Bisai, A. Bisai, V. K. Singh, Tetrahedron 2012, 68, $4541-4580$.

[10] a) Y. Hayashi, T. Itoh, N. Nagae, M. Ohkubo, H. Ishikawa, Synlett 2008, 1565-1570; b) M. Amedjkouh, Tetrahedron: Asymmetry 2007, 18, 390-395; c) M. Majewski, I. Niewczas, N. Palyam, Synlett 2006, 2387-2390; d) A. Córdova, W. Zou, P. Dziedzic, I. Ibrahem, E. Reyes, Y. Xu, Chem. Eur. J. 2006, 12, 5383-5397

[11] a) Y Lam, K. N. Houk, U. Scheffler, R. Mahrwald, J. Am Chem. Soc. 2012, 134, 6286-6295; b) M. Markert, U. Scheffler, R. Mahrwald, J. Am. Chem. Soc. 2009, 131, 16642-16643; c) U. Scheffler, R. Mahrwald, J. Org. Chem. 2012, 77, 2310-2330.

[12] S. S. V. Ramasastry, H. Zhang, F. Tanaka, C. F. Barbas III, J Am. Chem. Soc. 2007, 129, 288-289.

[13] S. S. V. Ramasastry, K. Albertshofer, N. Utsumi, C. F. Barbas III, Org. Lett. 2008, 10, 1621-1624.
651 
[14] a) S. S. V. Ramasastry, K. Albertshofer, N. Utsumi, F. Tanaka, C. F. Barbas III, Angew. Ch nt. Ed. 2007, 46, 5572-5575; Angew. Chem. 2007, 119, 56 ( Z. Jiang, H. Yang, X. Han, J. Luo, M. W. Wong, Y. Lu, Org. Biomol. Chem. 2010, 8, 13681377.

[15] A. Bassan, W. Zou, E. Reyes, F. Himo, A. Córdova, Angew. Che t. Ed. 2005, 44, 7028-7032; Angew. Chem. 2005, 117, 7190

[16] K. Rohr, R. Mahrwald, Org. Lett. 2012, 14, 2180-2183.

[17] B. M. Trost, C. S. Brindle, Chem. Soc. Rev. 2010, 39, 16001632.

[18] a) B. List, L. Hoang, H. J. Martin, Proc. Natl. Acad. Sci. USA 2004, 101, 5839-5842; b) M. B. Schmid, K. Zeitler, R. M Gschwind, Angew. CInt. Ed. 2010, 49, 4997-5003; Angew. Chem. 2010, 122, $51 €$ H. Zhu, F. R. Clemente, K. N. Houk, M. P. Meyer, J. Am. Chem. Soc. 2009, 131, 1632-1633; d) D. Seebach, A. K. Beck, D. M. Badine, M. Limbach, A. Eschenmoser, A. M. Treasurywala, R. Hobi, W. Prikoszovich, B. Linder, Helv. Chim. Acta 2007, 90, 425-471.

[19] a) P. H.-Y. Cheong, C. Legaut, J. M. Um, N. Çelebi-Ölçum, K. N. Houk, Chem. Rev. 2011, 111, 5042-5137; b) A. K. Sharma, R. B. Sunoj, Angew. Cher t. Ed. 2010, 49, 63736377; Angew. Chem. 2010, 122, 65 M. P. Patil, R. B. Sunoj, J. Org. Chem. 2007, 72, 8202-8215; d) F. R. Clemente, K. N. Houk, J. Am. Chem. Soc. 2005, 127, 11294-11302; e) C. Allemann, R. Gordillo, F. R. Clemente, P. H.-Y. Cheong, K. N. Houk, Acc. Chem. Res. 2004, 37, 558-569; f) F. R. Clemente, K. N. Houk, Angew. Chem Int Ed. 2004, 43, 5766-5768; Angew. Chem. 2004, 116, 589 S. Bahmanyar, K. N. Houk, Org. Lett. 2003, 5, 1249-1 Lग, h) L. Hoang, S. Bahmanyar, K. N. Houk, B. List, J. Am. Chem. Soc. 2003, 125, 16-17; i) K. N. Rankin, J. W. Gauld, R. J. Boyd, J. Phys. Chem. A 2002, $106,5155-5159$.

[20] In the absence of acidic protons in the reaction media, L-proline methyl ester yields racemic aldol adducts, see: A. Bøgevic, N. Kumaragurubaran, K. A. Jørgensen, Chem. Commun. 2002 620-621.

[21] a) M. B. Schmid, K. Zeitler, R. M. Gschwind, J. Org. Chem. 2011, 76, 3005-3015; b) C. Marquez, J. O. Metzger, Chem. Commun. 2006, 1539-1541.

[22] D. A. Bock, C. W. Lehman, B. List, Proc. Natl. Acad. Sci. USA 2010, 107, 20636-20641

[23] S. Bahmanyar, K. N. Houk, H. J. Martin, B. List, J. Am. Chem. Soc. 2003, 125, 2475-2479.

[24] H. E. Zimmerman, M. D. Traxler, J. Am. Chem. Soc. 1957, 79, 1920-1923.

[25] a) A. de Cózar, F. P. Cossío, Phys. Chem. Chem. Phys. 2011, 13, 10858-10868; b) C. Nájera, J. M. Sansano, Chem. Rev. 2007, 107, 4584-4671; c) G. Pandeym, P. Banerjee, S. R. Gadre, Chem. Rev. 2006, 106, 4484-4517; d) C. Nájera, J. M. Sansano, Angew. Chem. Int. Ed. 2005, 44, 6272-6276; Angew. Chem. 2005, 117, 6428; e) C. Nájera, M. G. Retamosa, J. M. Sansano, Angew. Chem. Int Ed. 2008, 47, 6055-6058; Angew. Chem. 2008, 120, 614 $\Omega$

[26] E. Conde, D. Brro, A. de Cózar, M. Sánchez, M. A. Vázquez, F. P. Cossío, Chem. Sci. 2012, 3, 1486-1491.

[27] L. M. Castelló, C. Nájera, J. M. Sansano, O. Larrañaga, A. de Cózar, F. P. Cossío, Org. Lett. 2013, 15, 2902-2905.
[28] a) A. Arrieta, D. Otaegui, A. Zubia, F. P. Cossío, A. DíazOrtiz, A. de la Hoz, M. A. Herrero, P. Prieto, C. Foces-Foces, J. L. Pizarro, M. I. Arriortua, J. Org. Chem. 2007, 72, 43134322; b) S. Vivanco, B. Lecea, A. Arrieta, P. Prieto, I. Morao, A. Linden, F. P. Cossío, J. Am. Chem. Soc. 2000, 122, 60786092; c) M. Ayerbe, A. Arrieta, F. P. Cossío, A. Linden, J. Org. Chem. 1998, 63, 1795-1825.

[29] CCDC-965082 (for exo'-L-10aa) contains the supplementary crystallographic data for this paper. These data can be obtained free of charge from The Cambridge Crystallographic Data Centre via www.ccdc.cam.ac.uk/data_request/cif. The absolute configuration of exo'-L-10aa was unambiguously assigned by considering the Flack parameter value: 0.008(6); see the Supporting Information for details.

[30] E. V. Anslyn, D. A. Dougherty, Modern Physical Organic Chemistry, University Science Books, Sausalito, CA, 2006, p. $507-523$.

[31] H. Lineweaver, D. Burk, J. Am. Chem. Soc. 1934, 56, 658-666.

[32] C. J. Rogers, T. J. Dickerson, K. D. Janda, Tetrahedron 2006 , $62,352-356$

[33] N. Zotova, L. J. Broadbelt, A. Armstrong, D. G. Blackmond, Bioorg. Med. Chem. Lett. 2009, 19, 3934-3937.

[34] D. C. Harris, Experimental Error in Quantitative Chemical Analysis, 8th ed., W. H. Freeman, New York, 2010, p. 51-67.

[35] N. L. L. Allinger, Molecular Structure. Understanding Steric and Electronic Effects from Molecular Mechanics, Wiley, Hoboken, N.J. 2010.

[36] a) MacroModel, version 9.9, Schrodinger LLC, New York, NY, 2012; b) F. Mohamadi, N. G. J. Richards, W. C. Guida, R. Liskamp, M. Lipton, C. Caulfield, G. Chang, T. Hendrickson, W. C. Still, J. Comput. Chem. 1990, 11, 440-467.

[37] J. P. Rickaert, G. Ciccotti, H. J. C. Berendsen, J. Comp. Physiol. 1977, 23, 327-341.

[38] M. J. Frisch, G. W. Trucks, H. B. Schlegel, G. E. Scuseria, M. A. Robb, J. R. Cheeseman, G. Scalmani, V. Barone, B. Mennucci, G. A. Petersson, H. Nakatsuji, M. Caricato, X. Li, H. P. Hratchian, A. F. Izmaylov, J. Bloino, G. Zheng, J. L. Sonnenberg, M. Hada, M. Ehara, K. Toyota, R. Fukuda, J. Hasegawa, M. Ishida, T. Nakajima, Y. Honda, O. Kitao, H. Nakai, T. Vreven, J. A. Montgomery Jr., J. E. Peralta, F. Ogliaro, M. Bearpark, J. J. Heyd, E. Brothers, K. N. Kudin, V. N. Staroverov, R. Kobayashi, J. Normand, K. Raghavachari, A. Rendell, J. C. Burant, S. S. Iyengar, J. Tomasi, M. Cossi, N. Rega, J. M. Millam, M. Klene, J. E. Knox, J. B. Cross, V. Bakken, C. Adamo, J. Jaramillo, R. Gomperts, R. E. Stratmann, O. Yazyev, A. J. Austin, R. Cammi, C. Pomelli, J. W. Ochterski, R. L. Martin, K. Morokuma, V. G. Zakrzewski, G. A. Voth, P. Salvador, J. J. Dannenberg, S. Dapprich, A. D. Daniels, O. Farkas, J. B. Foresman, J. V. Ortiz, J. Cioslowski, D. J. Fox, Gaussian 09, revision B.01, Gaussian, Inc., Wallingford CT, 2009.

[39] a) C. Lee, W. Yang, R. G. Parr, Phys. Rev. B 1988, 37, 785789; b) A. D. Becke, J. Chem. Phys. 1993, 98, 1372-1377; c) A. D. Becke, J. Chem. Phys. 1993, 98, 5648-5652.

[40] a) R. Cammi, B. Mennucci, J. Tomasi, J. Phys. Chem. A 2000, 104, 5631-5637; b) J. Tomasi, B. Mennucci, R. Cammi, Chem. Rev. 2005, 105, 2999-3093.

[41] a) Y. Zhao, D. G. Truhlar, J. Chem. Theory Comput. 2008, 4 1849-1868; b) Y. Zhao, D. G. Truhlar, Acc. Chem. Res. 2008, 41,157-167; c) Y. Zhao, D. G. Truhlar, Theor. Chem. Acc. 2008, $120,215-241$.

Received: February 2, 2015 
Densely substituted enantiopure proline esters obtained through $[3+2]$ cycloadditions catalyze aldol reactions. These synthetic organocatalysts produce different enantiomeric aldol adducts depending on the stereochemical dispositions of the substituents at distal positions with respect to the catalytic site. Design criteria are proposed for this kind of organocatalysts.

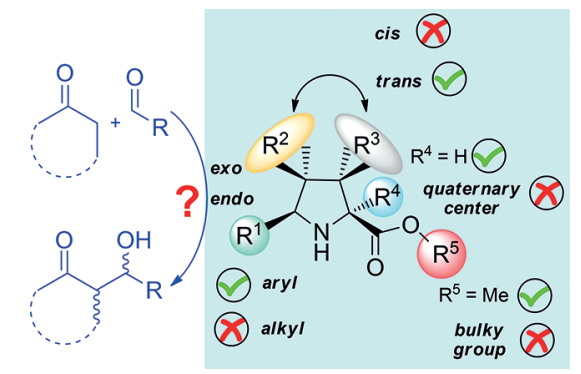

group 8
M. de Gracia Retamosa, A. de Cózar,

M. Sánchez, J. I. Miranda, J. M. Sansano,

L. M. Castelló, C. Nájera, A. I. Jiménez,

F. J. Sayago, C. Cativiela,

F. P. Cossío*

1-15

Remote Substituent Effects on the Stereoselectivity and Organocatalytic Activity of Densely Substituted Unnatural Proline Esters in Aldol Reactions

Keywords: Organocatalysis / Aldol reactions / Kinetics / Reaction mechanisms / Transition states 